\title{
The Balanced Scorecard and the Strategic Learning Process: A System Dynamics Modeling Approach
}

\author{
Steen Nielsen and Erland H. Nielsen \\ Department of Economics and Business Economics, Faculty of Business and Social Sciences, Aarhus University, Denmark \\ Correspondence should be addressed to Steen Nielsen; sni@asb.dk
}

Received 31 July 2014; Revised 27 March 2015; Accepted 30 March 2015

Academic Editor: David Bulger

Copyright ( $) 2015$ S. Nielsen and E. H. Nielsen. This is an open access article distributed under the Creative Commons Attribution License, which permits unrestricted use, distribution, and reproduction in any medium, provided the original work is properly cited.

\begin{abstract}
The main purpose of this paper is to improve on the conceptual as well as the methodological aspects of BSC as a quantitative model by combining elements from traditional balanced scorecard (BSC) thinking with the Systems Thinking. This is done by combining short and long term aspects of measurements. The result is then used to build and construct a balanced scorecard model for strategic learning with the specific aim to maintain satisfied customers and motivated employees. Strategic planning, operational execution, feedback, and learning are some of the most important key features of any performance measurement model. This paper aims to address not only the conceptual domain related to BSC, that is, learning and system dynamics causality and feedback, but also the methodological domain concept of precision solved by differential equations. Our results show how a potential move from a static strategic vision map to a linked and dynamic understanding may be not fully realistic but very useful for learning purposes. The new knowledge obtained from the learning feedbacks fertilizes both decision discussion and decision-making and what may be required in order to move to the next level of BSC and system dynamics integration.
\end{abstract}

\section{Introduction}

The paper is a response to the increasing interest in using BSC for decision making, for planning, and for strategic learning. Within the last few years, surveys have shown increased utilization of BSC for operational purposes and an increased interest in using BSC as a holistic decision and planning tool [1-3]. This is also documented in some of the related issues that are moving up the research agenda such as the increased interest in performance management systems in general [4] and the tendency towards and benefit of using and linking together several accounting models or practices [57], known as "packages of accounting models" [8]. We also note increased interest in "fact-based-decisions" discussed through the concept of "business analytics" proposed by Davenport [9]. And over the years, several recommendations have been given for researchers to draw upon a broader set of theories and disciplines when developing and testing hypotheses about different phenomena [4,10-14]. This would create what Merchant et al. [13] call "the reduction of disciplinary parochialism."
Despite the development of dozens of ideas and techniques for measuring not only intangible assets but also the connection between financial and nonfinancial performance measures, it is still an open question how these measures can be used for predictions $[15,16]$ and for improving future financial performance $[17,18]$.

BSC has developed into a comprehensive feed forward model called the "Closed-Loop Management System" [19, 20] in which relations between key performance indicators (KPIs) can be subjected to statistical tests and correlation analyses.

Also, the necessity of incorporating the dynamic effect into accounting has been pinpointed many times. For example, Teece [21] proposes the concept of "dynamic capabilities," that is, the ability to sense and to seize opportunities quickly and proficiently. Ittner and Larcker ([12], p. 401) specifically refer to system dynamics as a promising methodology by saying that "dynamic aspects of managerial accounting practices largely have been ignored in prior studies." Further, Norton ([22], p. 4) has referred to system dynamics by saying that "The systems approach is the perfect discipline to describe and 
evaluate business strategy. It is particularly appropriate for the complex structures which are emerging in the new economy." This is also indicated by the need for being both dynamic and flexible in order to accommodate strategic change [23].

Sundin et al. ([24], p. 237) also conclude this by saying that "So while there may not be a statistical causal relation, people may believe that there is one, and the MCS is built on that premise; as such it is a social construction. Consequently, researchers may not know whether people know or are even interested in whether the assumptions are statistically correct. So, even a belief in causality may be enough for a BSC and related mechanisms to work and if this belief dissipates, then potentially the basis for management control is reduced."

Directly related to Sundin's remark, on which we agree, we also hold the position that genuine causality (short term) may very well exist (not being a social construct) even if it is not possible to be established by normal statistical means.

The key research question in this paper is therefore "How can Systems Thinking add value to the discussion of BSC as a strategic learning model by increasing scope and differentiations within the conceptual domain, and at the same time increasing the precision with respect to measurement and control within the methodology domain."

The road for doing this is what Brinberg and McGrath [25] call an "experimental path" and in its final stage it will result in a "study-design" that could be used for future research as shown in Figure 1.

Or more specifically, we want to demonstrate how a decision-maker can use such a model for investigating a lean strategy by changing a few important KPIs using items such as nonlinear time-lags, causality, and feedbacks in the system dynamic setup. The process for obtaining this is what Brinberg and McGrath [25] call the "experimental path," where the main idea is to build a "study-design" and implement it by using it on a set of events within the "substantive domain."

The concepts of the system dynamic philosophy are primarily centered on a certain understanding of causality in a systems setting. System dynamics offers a new generic type of structural embedding for thinking about causality, where causes are essentially treated as pressures (rates) which, by integration and over time, change the states (levels) of the system, resulting in aggregate patterns of behaviour. Our research framework is shown in Figure 2.

Thus, system dynamics does not, and this is important, offer one "grand theory"; instead each model is a theory by itself. System dynamics is concerned with aggregate social phenomena and not individual actions. Due to the level of the aggregation aspect, system dynamics is closely linked to Simon's [26] "principle of bounded rationality," which draws attention to the cognitive limitations of the information gathering and processing powers of human decision-makers. Bisbe et al. [27] also discuss BSC as a model or as a construct which may be specified as either a formative model (i.e., there exists a census of the indicators required) or as a reflective model (i.e., the construct is a sample of interchangeable indicators).

By addressing the research question above, the paper makes three contributions. First, it demonstrates the use of Systems Thinking on a BSC model in a dynamic perspective,

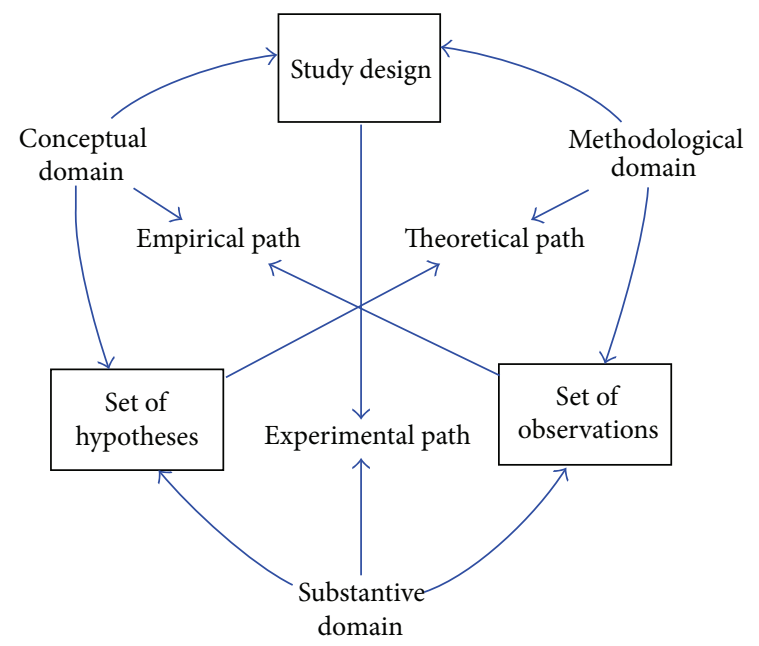

Figure 1: The Validity Network Schema (VNS) developed by Brinberg and McGrath [25].

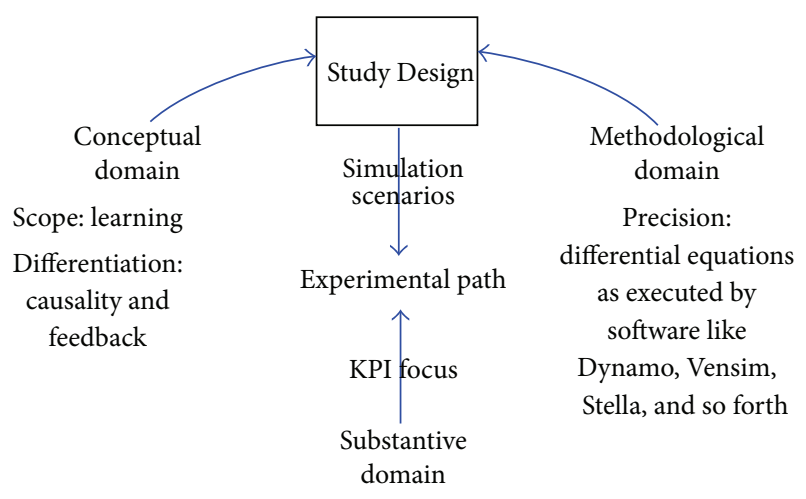

Inspirational basis, embodied by aspects of a real company

FIGURE 2: Our research framework.

incorporating the concepts of stocks and flows. In doing so, the paper also answers Ittner and Larcker's [12] call for using System Thinking for managerial practices and also Norton's [22] more specific idea of using system dynamics for BSC. Second, by focusing on "scope" and "differentiation" within the "conceptual domain," we demonstrate the feasibility of using Systems Thinking to increase the purpose area of BSC by supporting BSC with the facility of strategic learning and feedback, elements that have been on the research agenda for over thirty years $[28,29]$ and which were also pinpointed by the inventors of BSC $[20,30,31]$. Third, based on the formulation and the technical design of the model, we show that using the facilities of system dynamics for formal equations definitions including time-lags, causality, and feedbacks enables the decision-maker to evaluate potential elements in the financial perspective over a specific planning horizon, which would make BSC a unique managerial instrument in the future.

The rest of this paper is structured as follows. Section 2 presents the conceptual domain for BSC with focus on earlier 
literature related to valuation and measurement within performance. Section 3 deals with the methodology domain and BSC thinking related to the system dynamics modeling philosophy. In Section 4 we present the model building process and the "study-design". In Section 5 we design the strategic learning scenarios, and finally in Section 6 we discuss the results together with some conclusions and give suggestions for further research.

\section{A Literature Review: The Conceptual Domain}

2.1. Estimation Challenges between a Few Single Performance Measures. The purpose of this section is to review some of the specific measurement problems mentioned in the performance literature and related to a quantitatively designed BSC model. These issues include items such as type of estimation, cause-and-effect, time-lags, feed forward and feedback assumptions, and the strategic learning element. Kaplan and Norton ([19], p. 159) explain strategic learning as "effecting successful strategies meaning gathering feedback (double loop learning), testing the hypotheses on which strategy was based, and making the necessary adjustment." When we look at the period since the introduction of the balanced scorecard in 1992 by Kaplan and Norton and till now, we see that BSC has gone through different time stages or generations: from a simple 1st G. tool to what we now may call a 4th G. tool (see e.g., $[20,32-34]$ ). Also a 5th G. BSC model may now be derived from what Kaplan and Norton call an "analytics framework for BSC." Elements for "analytics" discussion are also included in Kaplan and Norton seminars (e.g., in 2015 in different brochures for conferences such as "The Important Role of Data Analytics in Strategic Performance Management" or "Bullet Proof Your Strategy using Business War Games"). And as the wording suggests, they not only point to the use of strategic simulation like in war games, but they also point to the optimization of the use of data by leveraging business intelligence and analytical tools and technology to gather the right data for the right decision.

Empirical estimation problems have always been an important topic in performance measurement systems. Anderson et al. $[35,36]$, for example, estimated that the average customer satisfaction in 77 Swedish firms was positively related to contemporaneous accounting return on investment but found weaker or negative relations in service firms. Another study conducted by Banker et al. [17] also found positive associations between customer satisfaction measures and future accounting performance. The importance of tradeoffs between a few metrics is also documented by two other studies at that point $[37,38]$.

The study by Ashton [37] used a sensitivity analysis based on empirical numbers and showed that a mere one percent change in each of sales growth, employee, and supplier value added for portfolio companies could give a 24 percent improvement in operations income, which should indeed sharpen the attention of managers intensively. Therefore, even small changes at root cause level can easily result in large changes in various operating variables [37].
Similar results are shown in Rucci et al. [38]. After extensive statistical refinement of a test model conducted by Sears, Rucci et al. [38] identified several key value drivers (e.g., that an increase in employee attitude has a direct impact on customer impression, and customer impression has a direct impact on the future accounting performance of individual stores). The study at Sears documented that an increase in customer satisfaction would lead to an estimated \$200 million increase in revenues and ultimately an estimated \$250 million increase in market capitalization (based on their current after-tax margins and price-earnings ratio). Both of these studies show the importance of trying to understand how performance metrics and measures interact.

In a state-of-the-art article, Ittner and Larcker [15] came up with a number of problems related to traditional financial measures. For example, (a) the lack of predictive ability to explain future performance, (b) systems only providing little information on root causes or solutions to problems, (c) missing focus on cross-functional processes within a company, and (d) the inadequate ability to find and measure the nonfinancial "value drivers." Supported by a number of surveys, Ittner and Larcker [15] also show that 75 percent of the senior quality executives felt under pressure to demonstrate the financial consequences of their quality initiatives, but less than 55 percent could actually relate their quality measures to operational productivity or revenue improvements. Only 28 percent could link customer satisfaction measures to accounting returns and only 27 percent to stock returns. They also found that the correlation between customer satisfaction and customer loyalty could only be shown up to a certain level; once a certain threshold had been met, further investments in customer satisfaction did not improve customer loyalty.

Ittner and Larcker [12] discuss common methodological and econometric problems and suggest the use of business models that link multiple value drivers in a causal chain of leading and lagging performance indicators as research opportunities. In 2003, Ittner and Larcker [39] found that return on assets was about 3 percent higher and return on equity was about 5 percent higher in companies using causal models compared to companies that did not use causal models, but they also found that only 23 percent of the 157 organizations in their study consistently built and tested causal models to support the definition of their performance indicators.

The authors also show positive effects from the strategic alignment processes. Finally, the authors point to the importance of the long term economic performance as the most powerful output for nonfinancial measures. At the same time it is important to base decisions on a well-established series of links and to develop a causal model based on the hypotheses in the strategic plan, collect operational data, and turn the data into information.

Dikolli and Sedatole [18] suggest a taxonomy for further empirical refinements of leading indicator relations that could improve the information content of different nonfinancial measures. They discuss (1) alternative measurements of 
the nonfinancial measures, (2) timing differences in the leading indicator relation (both the lag length and the persistence), (3) interactions between the nonfinancial measures and contextual variables affecting the leading indicator relation, (4) the functional form of the leading indicator relation, and (5) variables that play a mediating role in the relation between the nonfinancial measures and future financial performance. They test their taxonomy on the information content of website stickiness for future financial performance and find that website stickiness is positively associated with future return on assets and found a one-quarter lag length for the leading indicator relation. They further posit that the direction (i.e., the coefficient sign) of the relation between website stickiness and future financial performance varies across firms. Finally, Dikolli and Sedatole [18] suggest a number of opportunities for future research that could make nonfinancial measures more useful for decision-making and control. For example, when do alternative nonfinancial measures have implications for future financial performance, under which conditions do combinations of nonfinancial measures improve leading indicator predictions, or does the explanatory power and/or economic significance of leading indicator relations improve if one assumes functional forms that are nonlinear (e.g., curvilinear, kinked, or asymmetric), or what nonparametric tests are required and does a metric change with time?

However, Wiersma [40] tested two nonfinancial measures (absence frequency and on-time-delivery) both for their relative and their incremental information content to predict future financial performance and found that the two nonfinancial measures do not have more relative information content than lagged financial measures. Therefore, no support was found for the hypothesis that the relative information content of lagged nonfinancial measures increases compared to lagged financial measures when more lags were used. However, the two nonfinancial measures have incremental information content beyond the lagged financial measures for both future costs and future revenues. For future research, Wiersma [40] also suggests that focus should be on different lags between the nonfinancial measures and financial measures.

2.2. Further Extension of the Estimation Challenges for the BSC Framework. As documented in the section above, refinements and improvements have been discussed over the years when it comes to "simple" relationships between a few metrics. These are not trivial problems. So one should not expect that these problems will be less important or vanish when it comes to a whole set of metrics in a coherent framework such as the Balanced Scorecard, grouped in different clusters of metrics.

In BSC, however, the strategy is the pivotal point or compound variable in which the selection of KPIs must be done. A number of basic issues still exist, for example, what constitutes a BSC, how do we test the effect of a strategy, what is meant by "balance," and are there studies that document a positive effect from using BSC compared to companies not using BSC? Malmi [41] suggests that a measurement system can be considered a BSC when the measurement system includes both financial and nonfinancial measures and that the measures should be derived from strategy and should be categorized in perspectives. But even within these three boundaries several degrees of freedom exist.

However, beside the statistical techniques used in the literature mentioned above and suggested for testing various KPIs, factor analysis for selecting the most influencing KPIs [42] and the use of structural equation modeling for validating the relations between different perspectives [43] are also relevant.

The first question that arises is what constitutes a welldesigned performance measure or a BSC [44]. Several surveys have discussed some of the same or related questions, for example, the inadequacies in traditional accounting measures and their lack of predictive ability, that is, their missing information on root causes and their inability to capture key business changes, their problems of not reflecting crossfunctional processes, or their inability to influence the financial consequences of different actions [15, 45-47].

Another early point of criticism refers to the set of conceptual relations that specify the form of logical-causal pattern among KPIs and perspectives and is concerned with how the cause-and-effect in BSC should be understood and estimated as well as the time-lag discussion [48-51]. It has also been questioned whether the assumptions of BSC make the use of BSC inexpedient $[48,52]$.

Several attempts have been made to see if a statistical significance could be established between measures or between perspectives [50, 53] based on a Sims-Granger type of causality [54]. However, only limited support for this could be established. This may be caused by the fact that deep "naturegiven" causal relations are almost impossible to encounter in socioeconomic systems $[55,56]$. Instead, the concept of mental models as discussed within system dynamics [57-59] seems much more appropriate for modeling BSC in quantitative terms. The authors put up a number of propositions for future research including more focus on "learning by doing" which emphasizes the dynamic context of business and simulation. They also suggest that the design and use of the performance management model may be influenced by a financial feedback because all elements of the proposed control theory are dynamic.

A further question is if and how the strategy influences performance. The results of Chenhall [11] suggest that the influence of an integrative model on strategic outcomes has an indirect effect through the mediating roles of alignment of manufacturing with strategy and organizational learning. Specifically, the study shows that performance management systems will improve the strategic competitiveness if they focus on how goals, strategies, and operations are connected and attempt to provide an understanding of the interdependencies across the value chain and that strategies should be designed as such to assist in the organizational learning and feedback process. These problems may also be related to the classification mentioned by Speckbacher et al. [34], that is, which type (i.e., Generation) of BSC is used? The conclusion is that most criticism can be traced back to the definition and perception of the discussion of the cause-and-effect relationships inherent in BSC, and they again influence the definition 
of time and time delays between KPIs and perspectives. Ittner and Larcker ([15], p. 221f) also show problems related to both the relative importance of measures and the quantification of qualitative related data (nonfinancial data).

Another key question is what is meant by "balance" and the mechanisms through which "balance" promotes performance. A common view, perpetuated by early writings on the balanced scorecard concept $[30,31,60]$, says that "balance" is achieved by diverse measurement in the domains of financial performance, operational performance, performance for the customer, and learning and innovation. Kaplan and Norton $[31,60]$ argue that a balanced scorecard is not merely a collection of financial and nonfinancial measures in various categories (hard and soft values and short and long run) but that it is an integrated set of measures developed from a "theory of the business" that explicitly links the scorecard metrics in a causal chain of performance drivers and outcomes.

Another definition of "balance" would be the adjustment of some variables towards an "economic equilibrium." These forces or economic variables will remain at their equilibrium values in the absence of external influences. Economic equilibrium may also be defined as the point where supply equals demand. In a BSC context it would be the point where all the chosen KPIs create the optimal information flow to make the optimal decisions [7]. The issue of "balance" also includes the discussion of tradeoffs among multiple financial and nonfinancial performance measures. Or action taken to improve one measure may lead to short term or long-term declines in other performance measures [61]. Kaplan and Norton [31] also suggest the use of hurdles rates to ensure that managers do not receive bonuses when they overperform on some dimensions but underperform on others. In system dynamics, a "balanced equilibrium" means that all stocks in the system are unchanging, requiring their inflows and outflows to be equal ([62], p. 716).

Kanji [63] offers a solution to some of these problems such as tracking financial results while simultaneously monitoring progress in building the capabilities and acquiring the intangible assets needed for future growth and stability and reducing information overload. Other questions are where to set the system boundaries and how to include external measures, for example, to measure market shares and customer satisfaction.

Some research questions also focus on the documentation of the benefit of using BSC. Both de Geuser et al. [1] and Wiersma [2] have found a positive impact on organizational performance in companies using BSC, compared to companies not using BSC, and that the BSC has improved the integration of the management processes as well as empowered people. Wiersma [2] documented that BSC is also used for decision-making and coordination, for example, through the presumed cause-and-effect relationships between different measures and perspectives of the BSC. For future research, Wiersma [2] suggests a focus on different types of purposes that might require different BSC designs and the frequency of reporting information from the system. Malmi [41] reported that one month was the most commonly used reporting period, but Wiersma [2] advocates a more continuous and online feedback approach.
A relevant attribute for a metric is its predictive validity. From a management accounting standpoint, a crucial test is whether a broad set of nonfinancial measures such as employee satisfaction, employee turnover, product development cycle time, or supplier relations possess incremental ability to predict future financial performance after controlling of the predictability of past financial performance. Predictive validity is one of the key attributes of interest when selecting performance measures [15].

In summary, even though problems still exist for BSC, the framework has also documented its value for real companies. Moreover, much of the criticism that has been raised over the years-specifically related to the cause-and-effect and time lag assumptions - is, however, also true for other models within management accounting as such (e.g., an ABC model) and also within other research fields such as finance and logistics (see also [56]). Besides, part of the criticism was raised over 20 years ago, and improvements and refinements of the BSC model have been made.

However, one explanation why companies do not use more advanced statistical methods is probably that the companies do not have the expertise and skills to use specific economic modeling design or advanced econometrics (this argument is also present for not using "analytics" and bigdata; see, e.g., [64]). Solution suggestions put forward by researchers within this field are, for example, the use of timeseries analysis, forecasts, correlation, causal analysis, structural equation modeling, bootstrapping, or simulation. This stage may be called "the statistical" stage in business analytics framework.

The second stage is then to use the result from this stage as the input for a system dynamic modeling process. Such a stage has also been suggested by Ittner and Larcker ([12], p. 401) who said that "These issues (opposed to a simple recursive causal model) are almost impossible to examine in a regression framework, and generally require some type of system dynamics method." Specifically, the tradeoffs between KPIs (between short and long run) and their effects on performance are important which means that a good performance management system should balance short and long term objectives and should be parsimonious and contain only the metrics that truly must, or could, be traded off against each other. Looking both backwards and forward, Hoque [65] also suggests that future studies could investigate whether and how causal relationships among balanced scorecard perspectives could be the outcome of facilitating strategic organizational and employee learning and how this would assess the impact on organizational strategic outcomes.

\section{System Dynamics Thinking: The Methodology Domain}

System Thinking was first introduced by Forrester in 1958, as an example of a macroeconomic problem of production distribution. Applications have now expanded to environmental change, politics, economic behavior, medicine, engineering, management, planning, and other fields. Over the last 30 years, the use of system dynamics in relation to strategic 
management and strategic planning problems has increased considerably and helped management teams within a number of areas to formulate strategy and to improve individual and organizational learning $[66,67]$.

System dynamics is also a rigorous modeling method that enables us to build formal computer simulations of complex systems and use them to learn about and design more effective and practical organizations [62]. The main idea is that "you cannot just do one thing" without thinking that "everything is connected to everything else," which is also at the center of performance management systems and BSC. Smith [68] states that a system as a whole is made up of elements that continually affect each other but are supposed to operate towards a common goal, which is in line with the arguments from other dynamic researchers [69-71].

The system dynamics method utilizes modeling elements such as feedback, delays, and nonlinearities within the domain of delay-differential equations mathematics (http://en .wikipedia.org/wiki/Delay_differential_equation) in order to portray the dynamics of the closed causal loop structures that are believed to rule the phenomena underlying the study. System dynamics is traditionally concerned with the numerical solution to a given problem, that is, simulation based analysis, but in cases where the mathematical setup is relatively simple, analytic solutions are also a possibility $[72,73]$. System dynamics also utilizes econometrics in order to estimate the partial mechanisms that the system dynamics model consists of if sufficient data is available, although a fundamental conflict between system dynamics and econometrics has existed from the beginning.

As pointed out by Meadows ([74], p. 48f),

System dynamicists and econometricians are led by their paradigms to notice different problems and to strive for different kinds of insights into socioeconomic systems.

\section{And furthermore}

\begin{abstract}
"System dynamicists should know from their own theorems of system behavior that most aggregate systems possess significant momentum, and that within a short time horizon the relatively simple structural hypotheses of econometrics are usually quite appropriate. But the system dynamics paradigm tends to reject not only the possibility, but the utility of working within short time horizons. In the system dynamics world view the short term is already determined and thus unchangeable by policy. Furthermore, in system dynamics models policies designed only for short term gain often lead to long-term loss. These different ideas about what kinds of knowledge about the future are useful arise from basically different assumptions about the nature of social systems."
\end{abstract}

System dynamics is essentially a modeling methodology made up of two basic elements denoted as "level" and "rate", respectively, depicting the real world elements of "state" and "change of state." In other terminologies, the talk will be of "stock" and "flow" relations. Delays come about when certain relations exist between certain levels and rates. Various soft modeling setups exist [75], but none with such intensive focus on the dynamic aspects of the situation at hand as the closed loop thinking of system dynamics. Instead of thinking in terms of linear causality, one has to think in terms of closed loop causal structures; instead of just noticing that we have to cut the sales staff because revenue has declined, we should also notice that revenue has declined because our sales staff has been previously reduced. This constitutes one of many closed loops that should be taken into account when trying to figure out the potential dynamics of the future. However, only when viewing the full set of relevant causal closed loops is one able to identify the actual root causes to a given observed problem and thereby typically also its potential cure.

There are several ways to make closed loop causal thinking operational. One is to focus entirely on the times used for various purposes, which are delays, and build a dynamic simulation model for the situation that has to be analyzed. This leads to the usual process of verification and validation in order to extend or shrink the model to be most adequately sized with all negligible detail removed. Another line of approach to a situation that has to be analyzed is to incorporate a dynamic importance-focus in the modeling process right from the beginning. Such effort relies heavily on a common understanding and on a series of archetypical closed causal loop structures, which are easily identified by observed symptoms and are therefore ideal for communication between operational staff and model developers and model users [76].

To illustrate the contents of these headings, we will briefly describe two archetypes. "Balancing a process with delay" is by far the most important structure and is contained within the logic of almost any situation. It embodies the principle of general error correction behavior that is presumably the most widely used operative principle constantly utilized not only by all biological beings but also by most mechanical equipment designed for situation dependent operation. The importance of this fundamental dynamic principle lies in the crucial relation between delay and reaction, and depending on the relative settings of these two elements, the system may become unstable or stable, where stability usually is the desired behavior. "Limits to growth" is another very predominant archetypical dynamic structure where a process feeds on itself in the sense that a previous action has a self-reinforcing effect. Because our sales personnel do a good job, orders are increasing, and revenue is therefore increasing. This enables us to increase the sales staff whereby even more orders are generated "ceteris paribus" and no limits present. However, as orders increase, the production lead time may increase, whereby a counteractive effect comes into play, eventually reducing the revenue and thereby dampening the self-reinforcing mechanism or even reversing the effect. The point is that the limiting or dampening effect is typically somewhat elusive to those whom it affects the most, and it is furthermore delayed in an obscure way so that direct linear causal observations are virtually useless. A dynamic model of the whole situation is needed for proper analysis in order to get a clear picture, as will be shown later. 
As mentioned several times in the system dynamics literature (e.g., $[62,77]$ ), but only mentioned sporadically in the BSC literature, a BSC construct can be seen as a social system that acts and reacts in accordance with mental models as its behavior goes beyond that of the individual people in the system.

Therefore, the interdisciplinary elements embedded in BSC automatically also relate to broader organization studies as defined by Katz and Kahn [78] and their System Thinking and to March and Simon [79] and their analysis of organizational behavior as processes of choosing, decisionmaking, and problem solving. The important issue is to link the qualitative and the quantitative elements together, which constitutes the true power of system dynamics modeling [80]. Also scholars within the BSC thinking [11, 20, 81] have stressed that BSC should be used for decision-making to communicate between managers and to provide learningfeedback on decisions taken. These elements are clearly also the most important elements in relation to system dynamics $[55,82]$. According to Malmi [41], the key issue is whether the existence of a causal model behind measures really affects the benefits obtained from BSCs and, in particular, does the BSC also facilitate strategic learning and the use of a feed forward model insight, that is, as a forecasting model in practice? We think that system dynamics can make an important contribution in that direction.

A final finesse of the closed loop causal reasoning described above is that it relates directly to the system dynamics modeling tradition as it is implemented in, for example, Vensim, which is used for this project. Having formulated a specific model, Vensim automatically supports the generation and sorting out of the various interacting causal loop structures embedded in the dynamic model structure. Vensim is an interactive software environment that has been designed for the development, exploration, analysis, and optimization of simulation models [83].

\section{Building the System Dynamic Balanced Scorecard: The Study Design}

In this section we will build our study design by combining ideas from the conceptual domain and the methodological domain described earlier. First, we would like to mention a few studies that already use system dynamics for performance management/measurement and BSC in an accounting setup.

Akkermans and van Oorschot [84] show how time-lag and causal discussions from the BSC literature can be included into a system dynamics model. In close collaboration with a team from a company, Akkermans and van Oorschot [84] built a comprehensive BSC dynamic system model. However, their study does not include any financial perspective or indicators, contrary to S. Nielsen and E. H. Nielsen [85] who did include the financial perspective.

Warren [86] shows how successful strategic management of business and noncommercial organizations requires attention to how performance is changing through time and how resources and information flow at a point in time, a dependence that gives rise to feedback.
Barnabè and Busco [87] and Barnabè [88] also speculate on the potentials of the system dynamics methodology to contribute to the balanced scorecard design and implementation and come to the conclusion that system dynamics benefits BSC by better defining the concept of causality and second it becomes possible to develop a comprehensive approach to performance management and strategy formulation and strategy implementation. Finally, they suggest using mathematical computer models to test and simulate such assumptions to see their impacts on strategy implementation.

\subsection{Mapping the Company's Initial BSC Dynamic Thinking.} For our model design we will use elements and relations found in a real company for formulating a number of delaydifferential equations. We are simply borrowing definitions, variables, and some of the assumed associations from a real company in order to give our model some realistic flavor. We cannot, at the current stage, claim to be very close to reality. Therefore, we only introduce selected parts from the company's BSC model and qualitative considerations that are relevant for building a system dynamics model of a BSC as a version 1 attempt.

The company operates within the electrical engineering sector and is part of much larger international corporation. The company has developed customer focus programs with the aim of moving the company in the direction of what sometimes is referred to as "the lean enterprise" according to Womack and Jones $[89,90]$. The experiences and the effects from these programs have been very positive. In order to strengthen the project even more and in order to integrate the programs more strongly within the company's ordinary control system, the CFO initiated the BSC project. Instead of using BSC as a hierarchical and top down approach for managers as mentioned by Kaplan and Norton [31, 60], the company wanted to create a tool for department units on all levels that would enable them to look critically at their own activities. More precisely, the cornerstones of the company's dynamic model are (i) the notion of viewing the business in different perspectives, (ii) the support and control system for each department unit's own activities, (iii) the "cockpit" flight metaphor as the simulation presentation view for different performance measures, and (iv) the use of the company's IT presentation as a support system. The primary control philosophy as communicated by the company's president can be summarized by three concepts of decentralization: customer focus, productivity improvement, and competence development. The main idea was what the project director called "Management Control in Lean Enterprise using a Balanced Scorecard." More precisely, the company's overall objective for the control system was to gather information on the effects of reducing lead times in order to be able to maintain satisfied customers and still have motivated employees (e.g., Ittner and Larcker [15], p. 206). This was the background against which we, as researchers in understanding with the company, moved to the next version or level of transforming the company's performance based BSC excel model into a quantitative and time dynamic causal loop model setup.

In the first version of BSC, the company had in fact no intention of linking the measures; only the planned effect 
TABLE 1: Details concerning the company's BSC.

\begin{tabular}{|c|c|c|c|c|}
\hline Perspectives & Objectives & Outcome measures & $\begin{array}{c}\text { Short run average } \\
\text { interaction time frame } \\
\text { originating from previous } \\
\text { perspective (assumptions) }\end{array}$ & $\begin{array}{l}\text { Long run time expectations } \\
\text { frame with respect to full } \\
\text { impact of effects originating } \\
\text { from an earlier perspective }\end{array}$ \\
\hline $\begin{array}{l}(5) \\
\text { Financial }\end{array}$ & $\begin{array}{l}\text { To be able to satisfy the preferential } \\
\text { creditors before demands for } \\
\text { dividends to owners are met }\end{array}$ & $\begin{array}{c}\mathrm{EVA}^{\mathrm{TM}} \text {, profit, and } \\
\text { RoCE }\end{array}$ & $\begin{array}{c}\text { "Cause }(4) \\
\rightarrow \text { Effect(5)" } \\
\approx 6 \text { months on average }\end{array}$ & $\begin{array}{c}\text { "Cause }(1) \\
\rightarrow \text { Effect }(5) " \\
\approx 3-5 \text { years in full } \\
\end{array}$ \\
\hline $\begin{array}{l}\text { (4) } \\
\text { Customer }\end{array}$ & $\begin{array}{l}\text { To offer the best products timely so } \\
\text { that the customer wishes to remain a } \\
\text { customer }\end{array}$ & $\begin{array}{l}\text { Active customers, } \\
\text { customer loyalty, and } \\
\text { customer } \\
\text { recommendations }\end{array}$ & $\begin{array}{c}\text { "Cause }(3) \\
\rightarrow \text { Effect }(4) " \\
\approx 17 \text { months on average }\end{array}$ & $\begin{array}{c}\text { "Cause( }(3) \\
\rightarrow \text { Effect( }(4) " \\
\approx 2 \text { years in full }\end{array}$ \\
\hline $\begin{array}{l}\text { (3) } \\
\text { Process \& } \\
\text { supplier }\end{array}$ & $\begin{array}{l}\text { To have access to the right resources at } \\
\text { any time. To improve the flow from } \\
\text { procurement to shipment }\end{array}$ & $\begin{array}{l}\text { Finished inventory, } \\
\text { product work in } \\
\text { process, and machine } \\
\text { capacity }\end{array}$ & $\begin{array}{c}\text { “Cause }(2) \\
\rightarrow \text { Effect(3)" } \\
\approx 6 \text { months on average }\end{array}$ & $\begin{array}{l}\text { "Cause }(2) \\
\rightarrow \operatorname{Effect}(3) " \\
\approx 1 \text { year in full }\end{array}$ \\
\hline $\begin{array}{l}(2) \\
\text { Employees }\end{array}$ & $\begin{array}{l}\text { To have well-motivated and competent } \\
\text { employees and let the employees be } \\
\text { aware of the importance of } \\
\text { competition }\end{array}$ & $\begin{array}{l}\text { Staff utilization and } \\
\text { staff capacity }\end{array}$ & $\begin{array}{c}\text { "Cause }(1) \\
\rightarrow \text { Effect }(2) " \\
\approx 3 \text { months on average }\end{array}$ & $\begin{aligned} & \text { "Cause }(1) \\
\rightarrow & \text { Effect( }(2) \\
\approx & 1 \text { year in full }\end{aligned}$ \\
\hline $\begin{array}{l}(1) \\
\mathrm{R} \& \mathrm{D}\end{array}$ & $\begin{array}{l}\text { To ensure strong competitiveness and } \\
\text { be able to grow steadily, continuously } \\
\text { developing products and services }\end{array}$ & Rate of innovations & $\begin{array}{c}\text { "Cause (5) } \\
\rightarrow \text { Effect(1)" } \\
\approx 12 \text { months on average }\end{array}$ & \\
\hline
\end{tabular}

of the vision should be considered and connected (corresponding to what Speckbacher et al. [34] call a type II BSC). However, the linking of measures is at the very heart of any systems understandings, also the BSC approach, and combined with SDM it becomes a main objective.

The SDM way of dealing with relations over time between variables is twofold, short term partial interaction mechanisms (causality), and long term complex (nonpartial) resulting effects of the full system's interaction. To link variables over a substantial amount of time is always a tricky matter and the discussion about causality is often clouded in this relation. The point is that we have enough trouble realizing cause-and-effects relations partially and in the short run, not to mention cause-and-effects in the long run. These effects are most likely the combined outcome of very complex and possibly nonlinear dynamic interactions repeated a multitude of times. And this particular aspect of the linking of variables makes SDM quite useful. According to the SDM thinking, it is to some extent possible to partially observe the short term causality through changes in states (Rates and LEVELs), in principle over infinitesimal time instances.

The simulation of scenarios then unfolds the longer run perspective of causality by evaluating the tracks of the myriads of dynamic interactions that happen over this longer time horizon. The short term interacting effects are typically the modeling part (reality $\rightarrow$ model), whereas the longer term effects given certain specific initial perturbations (shift in policy or abrupt change in the initial state structure) can be seen as policy implications if nothing else is influencing the system. In practice, of course, this "ceteris paribus" assumption is not a realistic assumption, so these model based long term scenario projections should definitely be considered for insight primarily and rough verification of expected behavior. In the following, we define a model measure for these long run effects. The measure indicates the point when a given initial change in some of the perspectives ceases to have any influence (a kind of steady state consideration). This measure is denoted TtFI (Time to Full Impact). We also apply an expected measure of this TtFI variable (denoted ETtFI). To understand and control the model scenario simulations, it is important to study not only the situation where the two measures are in agreement, but also the situation where the two measures differ significantly.

For our system dynamics version 1 BSC we did, however, also form a number of causal loops and time delays between the KPIs and the five perspectives. The company first came up with rough approximate guesses of the individual perspectives' average time delays as shown in Table 1 (fourth column/"assumptions"), and they were calibrated in order to make the model a consistent and dynamic short/long run well-functioning system. Table 1 shows the company's five perspectives together with their objectives and outcome measures and the basic dynamic reaction-time assumptions/calibrations. Mission/vision, values, and a strategy are supposed to deliver their benefits over different time periods depending on the time lag between lagging and leading indicators. Discussions with the director of the BSC project revealed a rough scheme for the Expected Time to Full Impact (ETtFI) of the different events. The fifth column of Table 1 holds the ETtFI between the specified perspectives expressed by the company. The study design has been focused on obtaining consistency between the short run delay assumptions relative to the long run TtFI expectations in this version 1 BSC/SDM-model and is justified in the various specific table-functions employed in the model.

Clearly, the system dynamics model is set up according to an expected "steady state" behavior and, in practice, no system is left undisturbed so that it can reach the theoretical long 


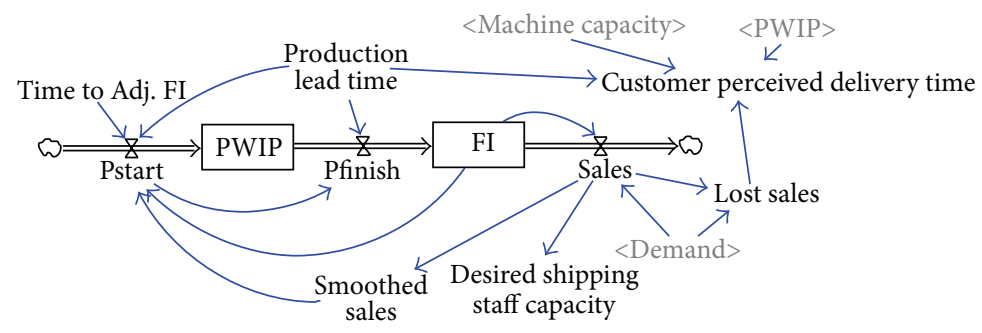

FIGURE 3: The logistics alias the "process \& supply" structure (SD-diagram).

run goals that the model might predict. In fact, any real world system is constantly trapped in a transient dynamic situation. And transients, however, can be very surprising in that even if we have set a goal for a given KPI higher than it is now, its path to the long run goal may go via an "initial" decline, sometimes referred to as "it has to be worse before it can be better." It is clearly the short run behavior that is of real interest when establishing the right normative evaluation setup for a particular KPI. When implementing their version of BSC, the company did face matching problems such as between the time of revenue realization and the time of expense. Activities in the research and development perspective therefore impacted the KPIs in the financial perspective with significant timelags. In our system dynamic version, these delays, which are measured in months, are incorporated either directly (also called a mediating effect, cf. [18]) as parameter values or indirectly as part of a trace validation. Below we will give a short outline of the building blocks of the system dynamics model that we have decided upon as the initial and very rough representation of the underlying BSC of the company. Finally, because of confidentiality and the complexity of the system dynamic BSC model, we keep the discussion at a more general level. In our description below, we have used the traditional and graphical way of showing feedback loops and relations in system dynamics. To be able to measure the effect on the long run from short run KPIs, an important assumption is to be able to estimate the tradeoffs between these two types of metrics (cf. also [61]). This emphasizes the need for determining which KPIs are short run metrics and which KPIs are long run metrics. If managerial actions to improve a performance metric do not imply a corresponding decline in short term financial performance, managers do not need to trade off one metric for the other. This missing assumption is called contemporaneously congruity which again creates no motivational distortion induced by a managerial reward system based on financial performance metrics.

4.2. Examples of Feedback Loops and Relations. The logistics alias the "process \& supply" part of the model is essentially a demand pull type structure, and the production delay is relatively small (small batch size) much in line with the lean thinking philosophy. Demand ("Demand") is satisfied directly from the finished inventory ("FI"), if possible, otherwise it is lost. As is very common in practice, production plans or requirements are generated on the basis of company internal data corresponding to "sales" and "finished inventory" data in this case. Production is started according to a smoothed level of sales and the adaptive closing of the finished inventory gap relative to a desired level of finished inventory holding. The production process (PWIP alias Production Work-In-Progress) is subjected to a fixed time delay. The logistics part is shown in Figure 3.

The production process is further subjected to what can be called "soft" capacity constraints (not shown graphically) in that any production level desired will be executed even if the machine or operator resources are not in place internally. It is assumed that such situations can be dealt with externally, although at a significantly higher cost. So the company wishes to control the machine capacity and adapt it in order to use as little outside capacity as possible and the number of operating staff is adapted so as to sustain either the internal capacity or the actual production level, which is the lowest of course. To finalize the "logistics" part of the model, there is a link to the "customer" part of the model in the form of a perceived delivery time by the customers or market.

As we are operating within a lean flow environment, the customers do not experience delivery delays if the production flow matches the demand flow well. When this is not the case and the finished inventory eventually gets depleted, the customers and the market experience a delivery delay greater than zero. It is assumed that the customers and market are able to roughly assess the fixed production delay under which the firm operates, to which the customers/market may even add some amount of time simply because expectations have not been fulfilled. The actual perception is thus an average delivery delay perception, but the perception is asymmetric in the sense that if delivery problems occur at a given time, and even if this is a very limited period of time, the perception continues to stick for a while after the event.

The customer part of the model is an important element in BSC and is essentially a simple macromarket model where the demand rate is generated based on a fraction of the number of customers currently in the "Customer Base." The dynamics of the customer base is a function of two variables, "Customer Loyalty" and "Recommendations," governing the outflow and the inflow of customers to the customer base, respectively. "Customer Loyalty" is also part of the "Recommendations" variable, which is under the influence of the "R\&D activities" in the company as well. The customer part is shown in Figure 4.

So customers are turned away (more outflow and less inflow) if the "Customer Loyalty" variable is low and vice 


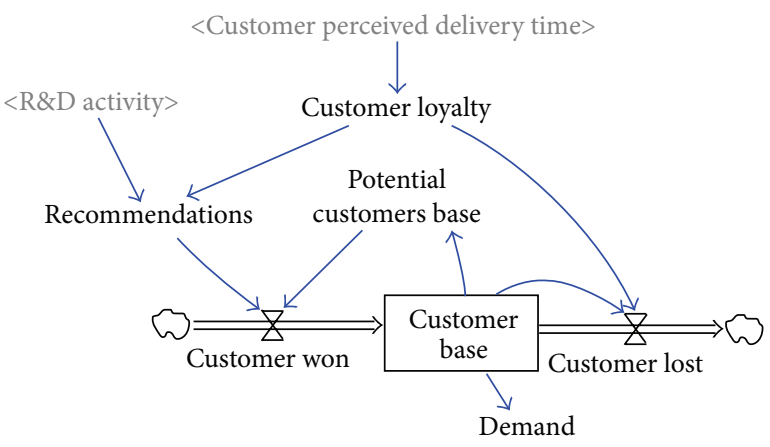

FIgURE 4: The customer structure (SD-diagram).

versa. The inflow is, however, increased if the " $R \& D$ activities" variable is high. In this model, "Customer Loyalty" is entirely a function of the delivery delay perception described above, which then is the link to the logistics part of the model. Both the employees' part of the model and the R\&D part of the model are modeled in a similar simple fashion just to get a starting point.

The financial part of the model is, of course, linked directly and indirectly to all other system dynamic parts of the BSC. The financial part is a lagging perspective and takes the various state variables and summarizes them into known financial variables such as Profit, RoCE (Return on Capital Employed), EVA ${ }^{\mathrm{TM}}$ (Economic Value Added) and average unit costs, just to mention a few possibilities. In BSC all KPIs in the financial perspective are characterized as lagging indicators whereas all the previous indicators are known as leading indicators. $\mathrm{EVA}^{\mathrm{TM}}$ seems to be a relevant financial measure, partly because of its association with stock returns and partly due to its use as an economic value measure for internal decision-making, performance measurement, and compensation for improving organizational performance [15]. The financial part is shown in Figure 5.

Finally, the individual parts above (whether shown or not shown graphically) are linked together to translate the causal loops into a complete dynamic model. Actual parameter setting is done by calibration in order to obtain a system that is roughly able to reproduce the ETtFIs from Table 1. This is only a first order trace validation, but if we combine this validation with a check ensuring that the magnitude of the calibrated parameters that govern the individual structural relations of the model is realistic (and preferably close to the initial Avg.-Delay guesses from Table 1), the model is definitely useable as a first attempt model.

The dynamic and integrated construct makes it possible to study simulation feedback and mechanisms and to obtain increased strategic insight as well as performing real-time research. Strategic learning consists of gathering feedback, testing the hypotheses on which the strategy was based, and making the necessary adjustments. And the BSC provides managers with a tool to do just that [19]. If, for example, a company's employees have delivered on the performance drivers (e.g., reduced lead times and increased capacity), then their failure to achieve the expected outcome (e.g., higher
$\mathrm{EVA}^{\mathrm{TM}}$ ) signals that the links or loops behind this strategy may not be valid.

The results of the strategic simulation can be used in discussions with different managers in all fields and functions with the main purpose of learning. The complete BSC model in a system dynamic layout is shown in Figure 6.

Observe that our model operates on a fixed delay ("Production Lead Time") in relation to the production process. Therefore let "PLT" denote the "Production Lead Time" constant. The full dynamic model can then be presented in vector terms by denoting $\mathbf{Y}(t)$ the vector of the following six level variables $(F I(t), P W I P(t)$, Machine Capacity $(t)$, Skills $(t)$, $\operatorname{Staff}(t)$, and Customer Base $(t))$ as a delay-differential set of six equations given as follows:

$$
\frac{d \mathbf{Y}(t)}{d t}=\mathbf{f}(\mathbf{Y}(t), \mathbf{Y}(t-P L T))
$$

In summary, this procedure is an accepted way of building and conducting system dynamics in organizations [66, 67]. For strategic simulation and learning especially, system dynamics is ideally suited for the operationalization of certain concepts within the strategy, more specifically within the control of intangibles, interdependencies, and the feedback and loop elements [28, 71, 91].

\section{Strategic Learning Scenarios and Simulation}

With reference to Figure 2, the last step in our study design is to do a number of simulation scenarios to complete the experimental path. The idea is to show and analyze four strategic learning scenarios based on the assumptions described in the previous sections. Strategic learning is important for successful application of BSC and for being able to test and adapt the company's strategy and to see if it is possible to obtain a planned profitability for the survival of the company $[3,20$, $31,60,81]$.

5.1. Strategic Learning. In the BSC context, feedback and learning mean the ability to know at any point in time whether the formulated strategy does, in fact, work, and if not, why [19]. In today's turbulent environment, it is not enough for companies only to be aware of differences between plans and actual results, as in a single loop learning model; the companies must constantly be aware of arising threats and opportunities that may lead to changes in the assumptions of the managers and employees about the proper strength of reaction $[19,29,92,93]$. The cost-effective way to obtain this double loop learning knowledge is simply to do experimental studies based on simulation models. The process of the double loop learning idea consists of gathering feedback, testing the hypotheses on which the strategy was based, and making the necessary adjustments. The future cannot be predicted, but the learning scenarios can serve to change the microcosm of managers and thereby the way these managers see and understand the world $[92,94]$.

The system dynamics modeling method offers the possibility of testing scenarios $[62,91,95]$ and learning without having to pay the price of real failure. 


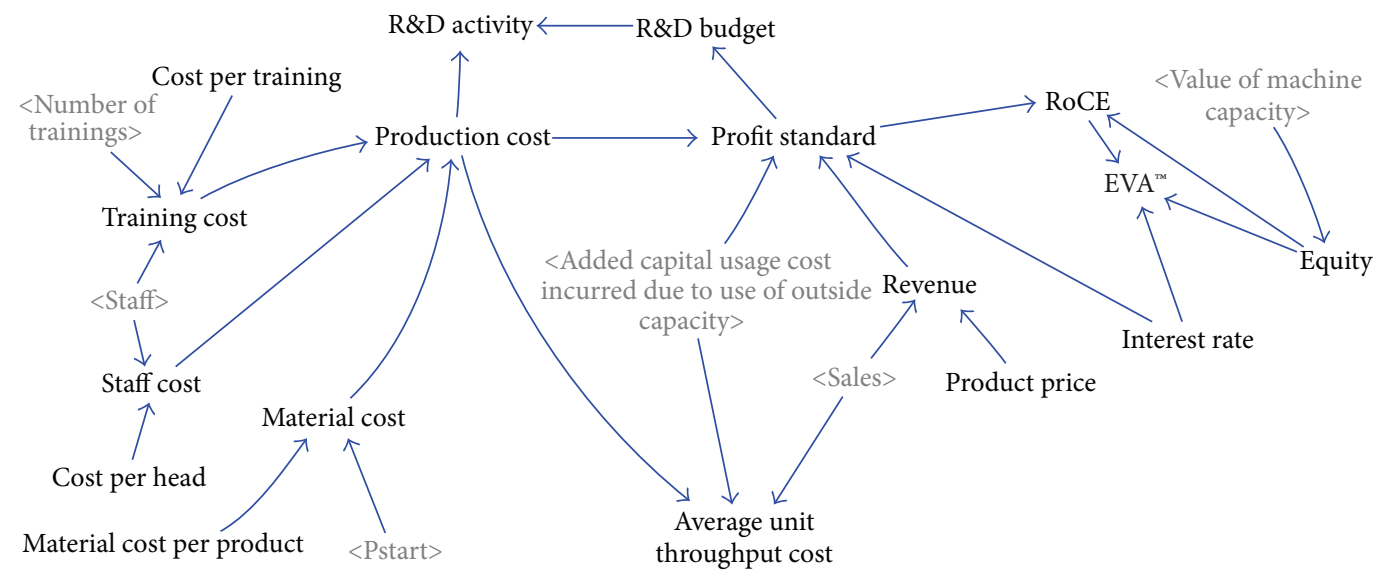

FIgURE 5: The financial structure (SD-diagram).

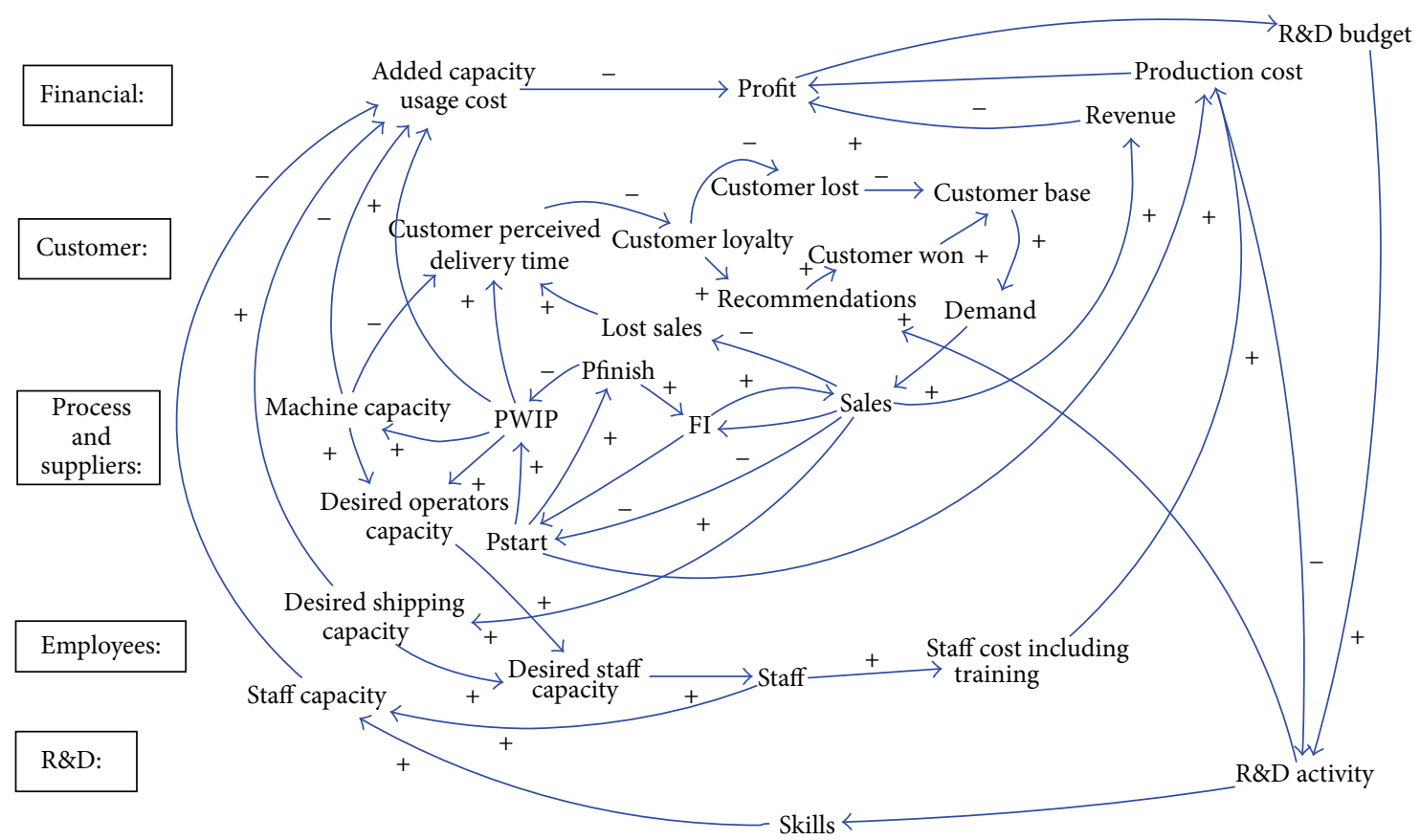

FIGURE 6: The BSC converted into a system dynamic model structure (SD-diagram).

The layouts of the simulation experiments in the system dynamics model environment can be customized for the specific use and purposes, for example, as separate graphs, numbers, and colors [58]. We have chosen a cockpit dashboard layout much in line with the company's own idea and in line with Kaplan and Norton's pilot cockpit metaphor [96]. The facility in the Vensim gives us the possibility to make a layout that immediately recognizes the dynamic change over time for each performance measure at any time for a five-year period. This way of visualizing results also corresponds to the reporting idea of visual management and box score in lean thinking and allows operational factors, capacity, and financial metrics to be shown in an easily understood graphical format $[97,98]$. To keep the simulation scenarios focused, we have conducted simulation interfaces of four strategic learning experiments related to a lean setting in order to test the effect on the EVA ${ }^{\mathrm{TM}}$ metric used by the company.

We have chosen a full model including the company's five perspectives, supplemented by a specific "control lean perspective" proposed by the company for which both essential input parameters and the resulting output performance measures can be shown as graphs and trends.

As we wish to simulate actions aimed at reaching a long run goal, two questions come to mind. Does the system have the right structural properties and are the current "initial" conditions appropriate in order to lead us towards the expressed desired long run goal?

Even though it may be difficult for a company to choose the right initial settings from the very start, it is important that the company has some idea of the way in which it wishes 
to progress. In particular, if certain KPIs have to take some major detours in order to get close to the stated long run targets eventually. If not seen in the correct dynamic context, such detours might be misinterpreted. To illustrate the effect of structural elements in a modeled BSC setup as well as initial system states on the actual path of certain KPIs, we will use a general long run goal setup which says that EVA ${ }^{\mathrm{TM}}$ should at least be non-decreasing and preferably following a maximum path in the long run. In the simulation below, we use four lean input parameters: "FI initial value" (i.e., finished inventory value), "Time to Adj. FI" (i.e., time to adjust the finished inventory level), "Machine Capacity initial value" (i.e., machine capacity level), and "Production Lead Time" (i.e., production lead time). These four KPIs are main input variables according to the company's concept of "Management Control in the Lean Enterprise using a Balanced Scorecard", that is, information about the effects of reducing lead times in order to be able to maintain satisfied customers.

5.2. Simulation Results. The structural change setting will focus on two reaction parameters in the system, production lead time and finished inventory adjustment speed, whereas the initial state settings will deal with the levels of finished inventory and machine capacity, respectively. The structural changes are all relevant in a lean environment [97]. The model is formulated as a monthly model over a five-year period, which is seen as a normal strategic period for BSC [20,99]. For our preparation of the company's strategy for operational simulation, we have used the design methodology of Collis and Rukstad [99] who describe the strategy as three critical elements: (1) Objective (O): the end goal that the company wants to reach such as a specific percent of $\mathrm{EVA}^{\mathrm{TM}}$ or RoCE, (2) Advantage (A): the tools or means applied to this, for example, that the company wants to be different or better than its competitors, and the (3) "Scope" (S): the area or the niche in which the company wants to operate, for example, a specific target or a customer segment. When we apply this procedure to the company, the strategy formulation would look like the following:

"We (the company) want a steady growth in net profit (O), a reduction of all cycle times by $50 \%$ each year compared to the previous year $(A)$, to be able to keep our satisfied customers and to be able to maintain and motivate our employees $(S)$.”

5.2.1. First Scenario. Based on this definition of the strategy the company's BSC concept is the main "controlling tool" that produces KPIs that put the company in a position to focus on the idea of the lean enterprise. In this first scenario the company's "Production Lead Time" is set to six months. This is quite a lengthy production time span and though the model is a "pull" based logistics structure, it does not quality as very lean at the outset due to this production lead time. The outcome is shown in Figure 7.

Figure 7 definitely calls for a few comments. Besides being "not too lean," the "Process \& Supplier Perspective" together with the "Lean Perspective" shows a production setup that is subject to a general production capacity increase in order to meet market demands. Though the level of demand is almost constant and only slightly oscillating, the production start rate is oscillating quite considerably which indicates that there is some bullwhip at work. The bullwhip concept has its roots in Forrester's Industrial Dynamics [100]. Since the oscillating demand magnification upstream of a supply chain may resemble a cracking whip, it became famous as the bullwhip effect and is seen as one of the most important side effects of the lean environment [97]. The "Customer Perspective" shows why the demand is slightly oscillating as both "Customer Loyalty" and "Recommendations" are dropping off regularly. This means that there must be recurring delivery problems and the production response is almost forced to be of an "agile" type production, where the "agility" property is sought obtained by having sufficient capacity. The "Financial Perspective" shows an almost constant profit, but decreasing EVA $^{\mathrm{TM}}$ and RoCE and finally an increasing "Unit Throughput Cost". This is a system with a grim long run perspective that is definitely not desirable at all.

5.2.2. Second Scenario. According to lean and JIT thinking $[97,101,102]$, all problems should simply vanish if the "Production Lead Time" is arranged so as to go towards zero. In our model it suffices to let "Production Lead Time" decrease to three months instead of six months. The dynamics of the system gets very well behaved and quite nice and much smoother to the eye, as can be seen in Figure 8.

The bullwhip effect seems to have disappeared totally and the financial measures seem most pleasing. Profit, EVA ${ }^{\mathrm{TM}}$, and RoCE are all increasing in a steady manner and the "Unit Throughput Cost" is steadily decreasing. This is obviously the ideal situation and performance management would be a piece of cake in such a world, but often there are physical limitations to the sufficient lowering of the "Production Lead Time". In lean, the throughput unit cost is a simple performance measure based on an average calculation in line with other measures and is not seen as a specific cost signal for the price as is the case within an activity-based costing method, for instance [97].

5.2.3. Third Scenario. The "Time to Adj. FI" was set to four months in the first scenario. Surprisingly, decreasing this parameter has no positive effects at all. So agility is not the right cure given the way the system is working in this example. Doing the opposite, that is, increasing the "Time to Adj. FI," has a distinctly positive effect as can be seen in Figure 9, however.

This solution also seems to eliminate the bullwhip effect and it gets all the financial measures on the right long run track. The solution is attractive as it is primarily a behavioral change instead of a physical change, but as can be seen from a closer look when comparing Figure 9 with Figure 8, it is not completely the same dynamic result. We still see short run ripples that did not show up when lowering the "Production Lead Time", and these ripples certainly give rise to a slightly more complicated performance management situation. Take, for example, the "Financial Perspective" and the dynamic path of the "Unit Throughput Cost", first it moves in the right direction (decreases), but around month 5 it begins to 
The BSC- "cockpit" for monitoring system performance

Process and supplier perspective:

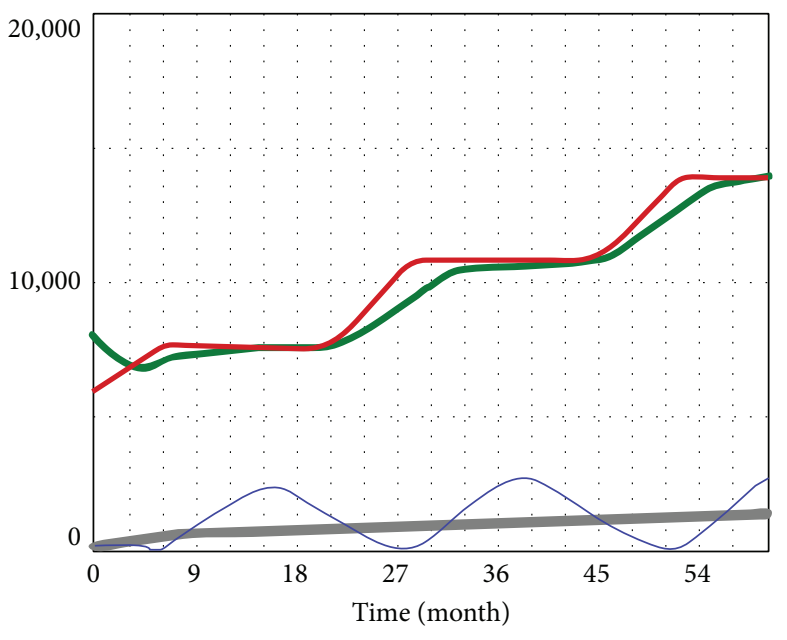

$\begin{array}{ll}\text { - FI: current } & \text { Machine capacity: current } \\ \text { - PWIP: current } & \text { Staff capacity: current }\end{array}$

Financial perspective:

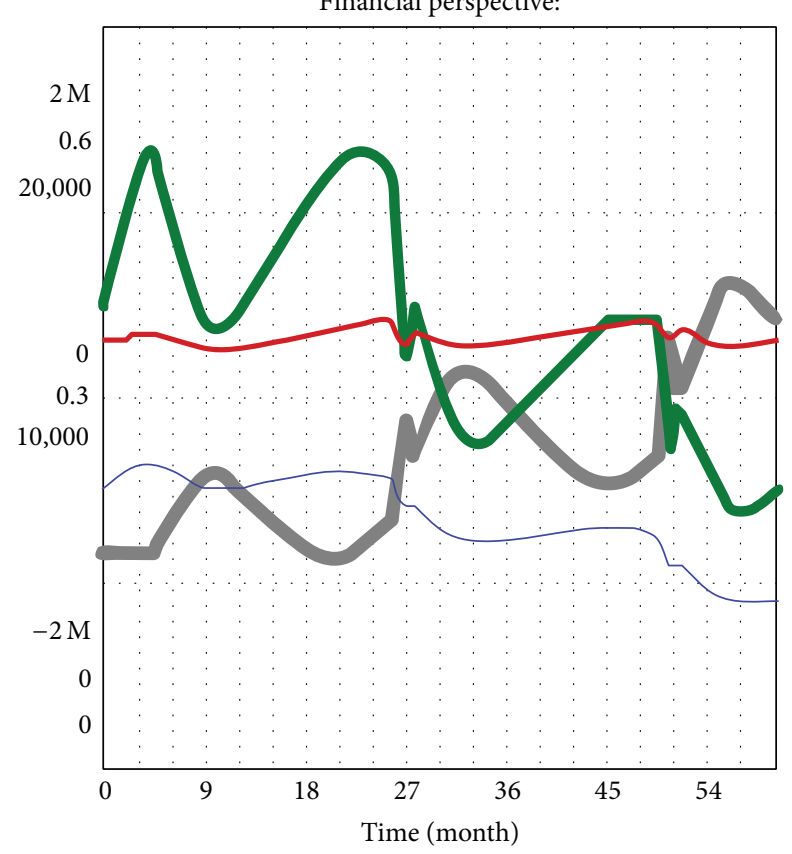

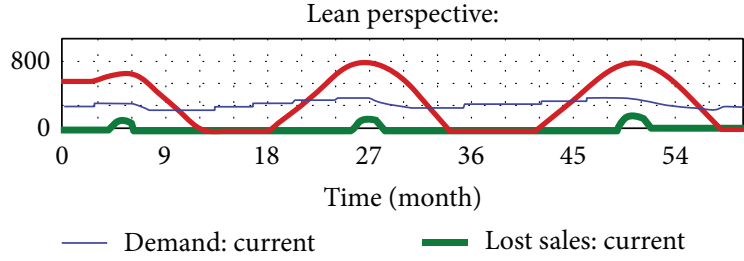

- Demand: current

Lost sales: current

- Pstart: current

Customer perspective:

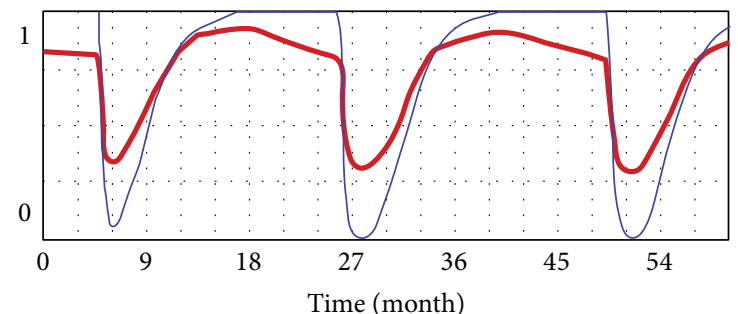

- Customer loyalty: current

— Recommendations: current

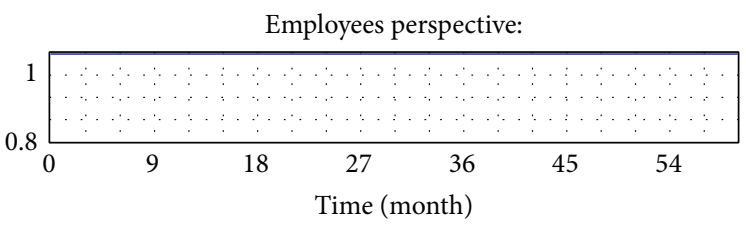

—_ Staff utilization: current

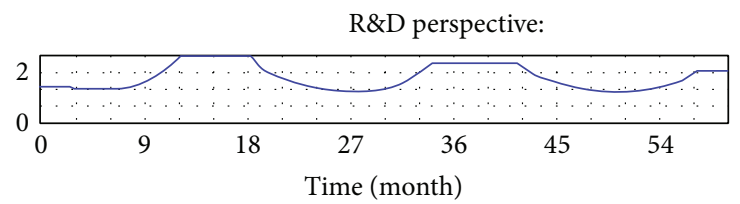

"R\&D activity": current

$<$ FI initial value $>$

$<$ Time to Adj. FI $>$

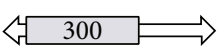

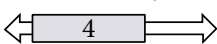

$<$ Machine capacity initial value $>$ $\stackrel{\leftrightarrow}{\longrightarrow}$

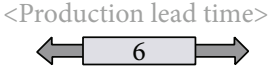

$\begin{array}{ll}\text { EVA }^{\mathrm{m}} \text { : current } & \text { RoCE: current } \\ \text { Profit standard: current } & \text { Unit throughput cost: current }\end{array}$

Figure 7: The first strategic scenario.

increase. Seen in a longer perspective this is, however, only a temporary setback. To know when "bad" signals are not really bad signals, but only some temporary ripple in a good development, is maybe the most compelling argument for actually trying to model BSC setups quantitatively. By the way, lean and agile are not always the answers to everything; a more calm and smooth production strategy might sometimes do the trick.
5.2.4. Fourth Scenario. In this last scenario let us return to the first scenario and take a closer look at the current state situation; in this example the FI $=300$ units and make a buyoperation from an outside producer of 550 units such that our new initial finished inventory (FI) amounts to 850 units. We face a constant tradeoff consideration between either spending money on inventory or on capital acquisition; the following example illustrates this situation where the finished 
The BSC_ “cockpit" for monitoring system performance
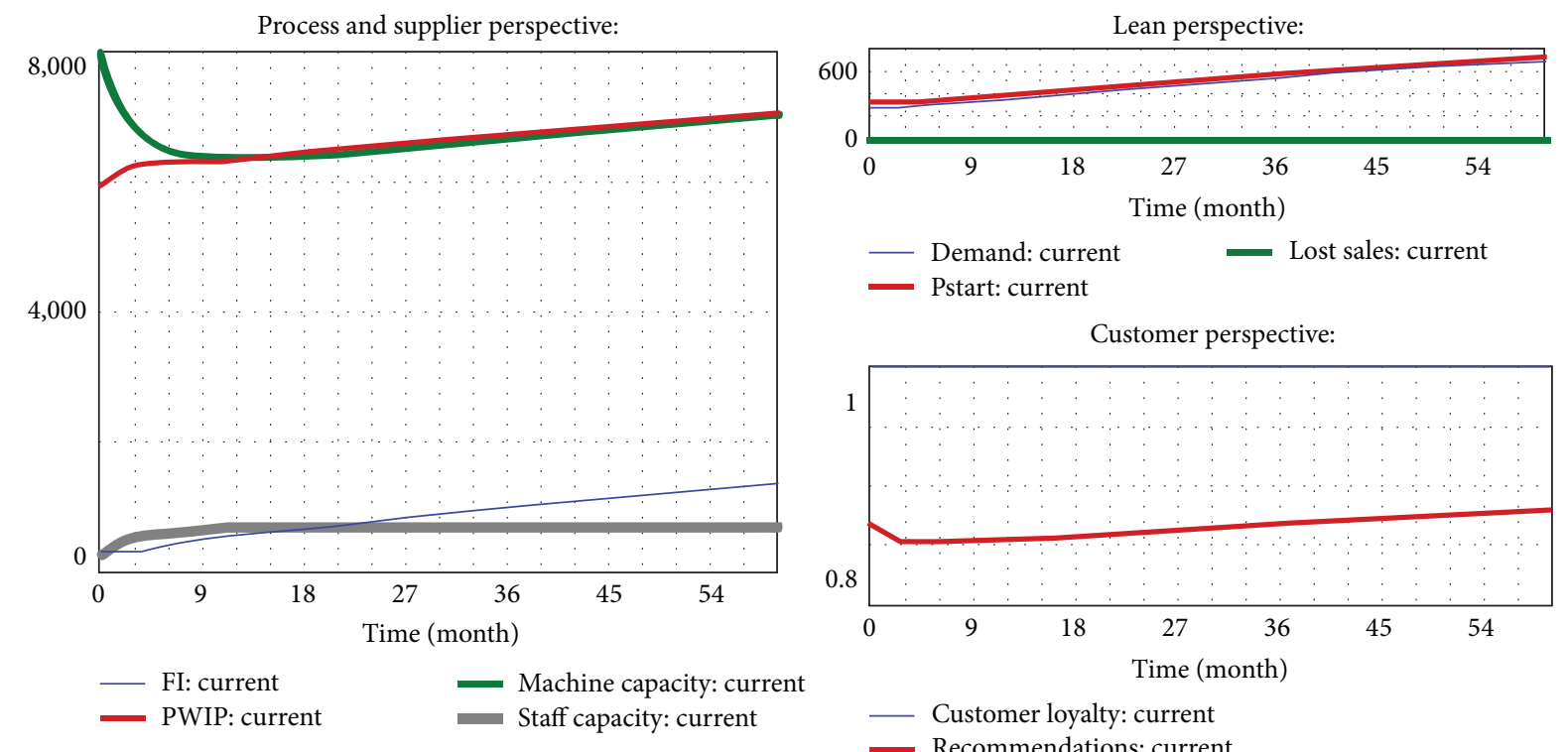

Financial perspective:

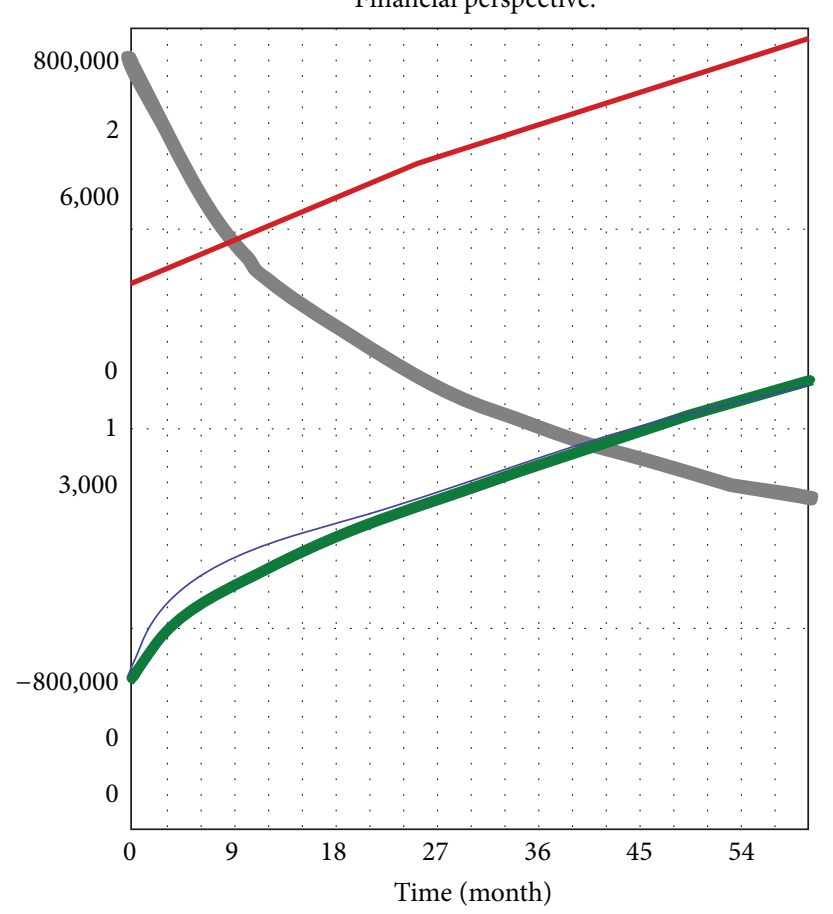

- Customer loyalty: current

— Recommendations: current

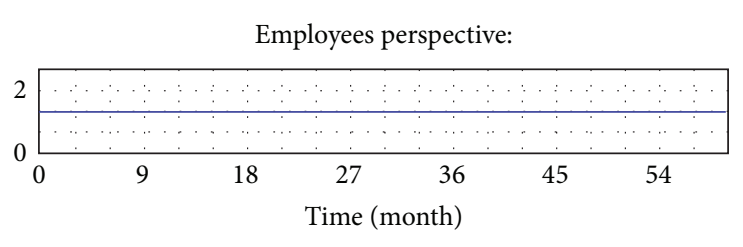

_ Staff utilization: current

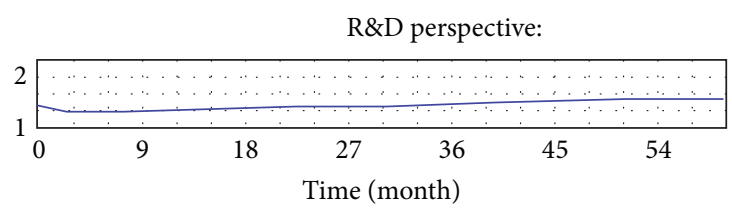

_ "R\&D activity": current

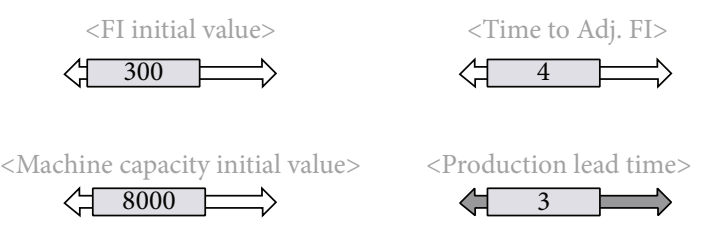

\begin{tabular}{ll} 
EVA $^{\mathrm{Tm}}:$ current & RoCE: current \\
\hline Profit standard: current & Unit throughput cost: current
\end{tabular}

FIGURE 8: The second strategic scenario.

inventory is infused initially. The result can be seen in Figure 10.

Surprisingly, it seems that even with the original settings of the "Production Lead Time" and "Time to Adj. FI" all problems have disappeared. This clearly indicates that the problems shown in the "first dynamic scenario" were primarily generated by an inadequate finished inventory situation given the market reaction built into the model. The insufficient finished inventory leads to a customer behavior that generates certain fluctuations in the demand, which in turn destabilizes the whole production setup. Clearly, setting a lower value for the "Production Lead Time" or a higher value for the "Time to Adj. FI" or both is probably a more robust solution, but relevant time to time FI infusions can obviously also do the job.

Given the company's lean strategy, the company should focus on improving productivity and increasing performance and flexibility and thereby create better value for its customers. 
The BSC_-"cockpit" for monitoring system performance
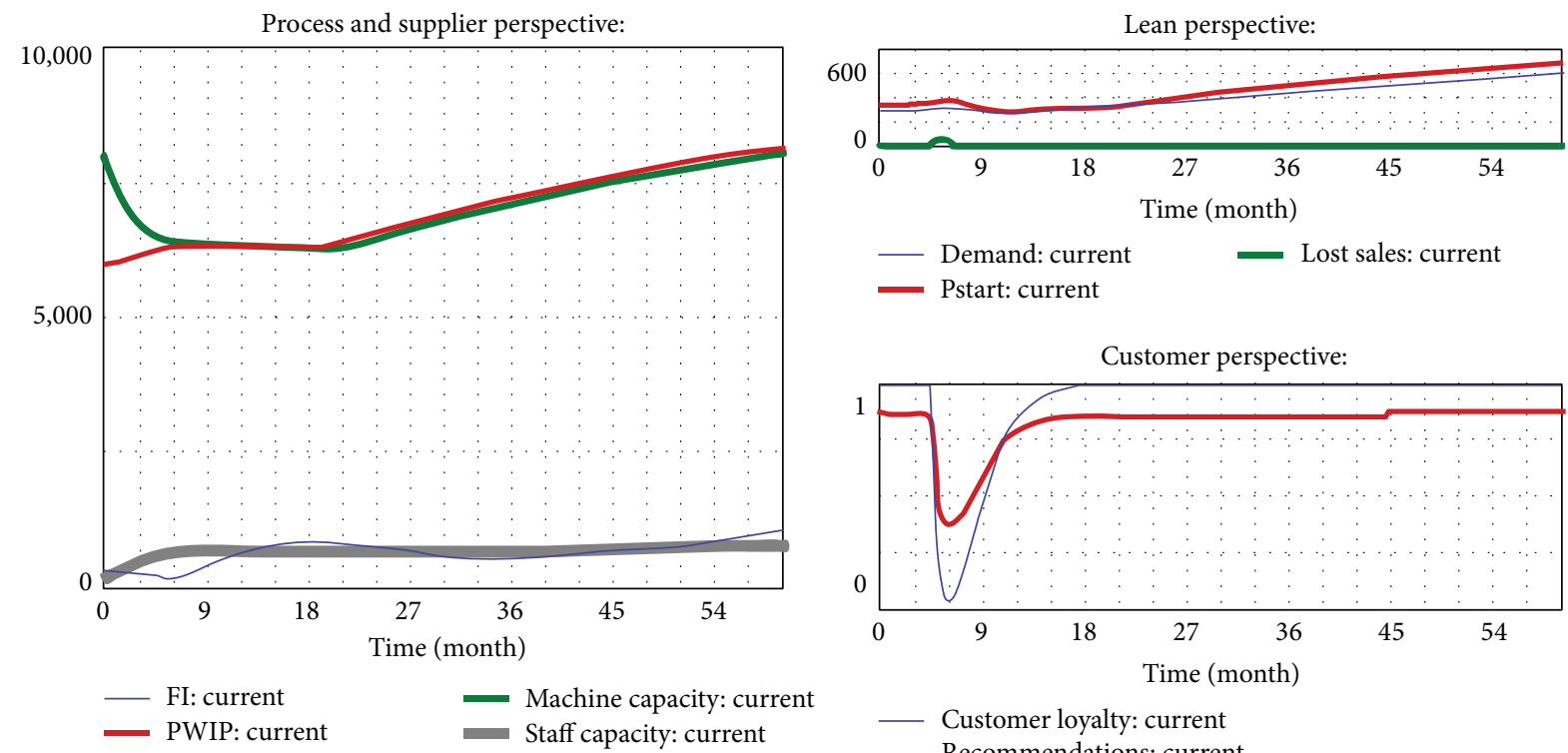

Financial perspective:

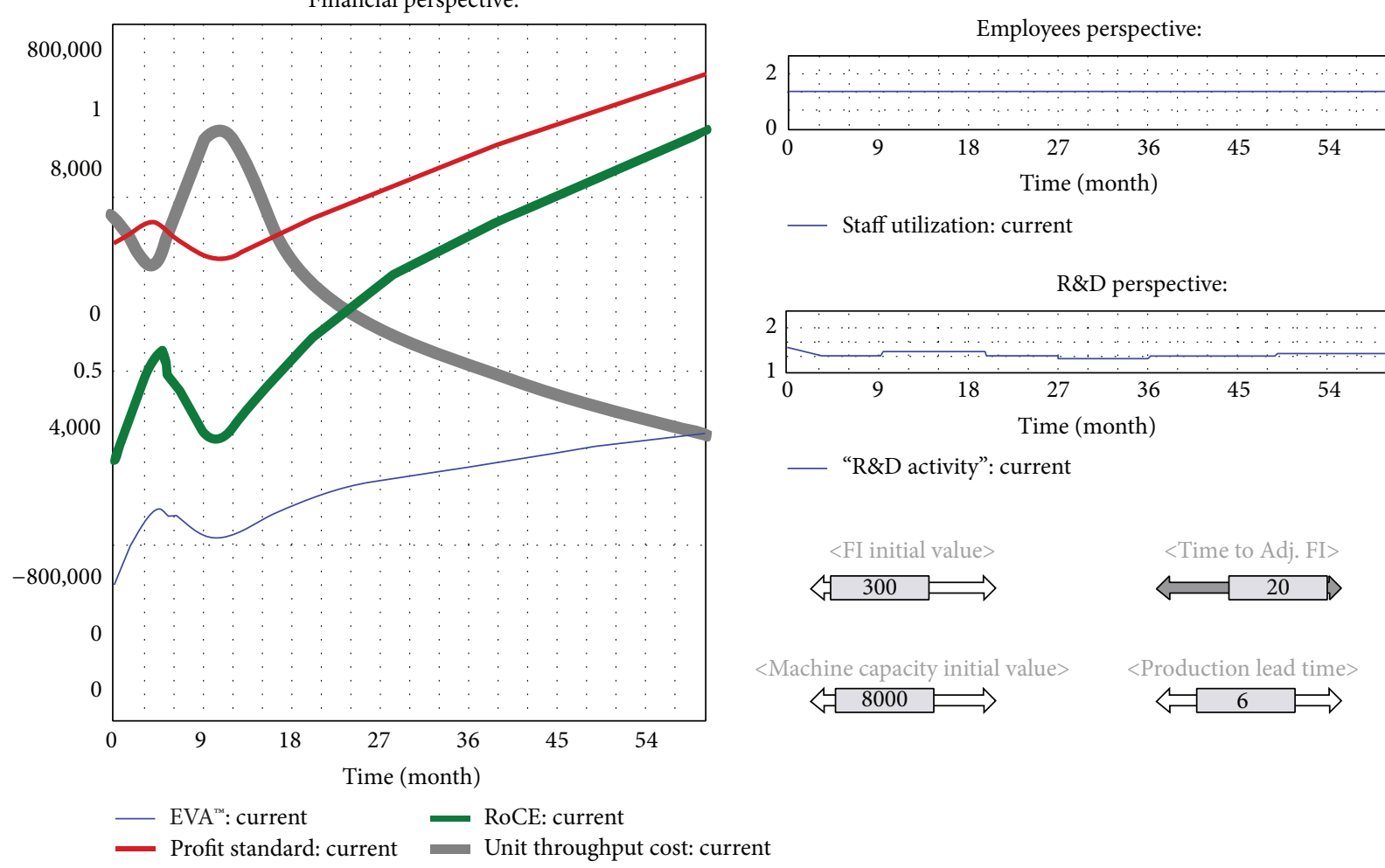

FIgure 9: The third "Changed Behavior" scenario.

The main conclusion to be drawn from these four strategic dynamic scenarios is that structural parameter settings as well as initial system state values can have a significant impact on the dynamic path that the system embarks upon. In a lean environment, structural parameters such as lead times and reaction speeds and the links between such parameters increase the complexity tremendously. The structural parameters are often deeply rooted institutional factors or they may be given by physical limitations (as may often be the case with lead time), so it may be hard if not impossible to change them. It is, of course, sometimes necessary to make structural changes. As seen in the "Inventory Infusion" scenario, however, a sudden (the increased initial value) infusion of extra inventory simply makes the system behave dynamically quite smoothly given its structural settings that otherwise result in very oscillatory dynamics. In some cases, 
The BSC_ “cockpit" for monitoring system performance
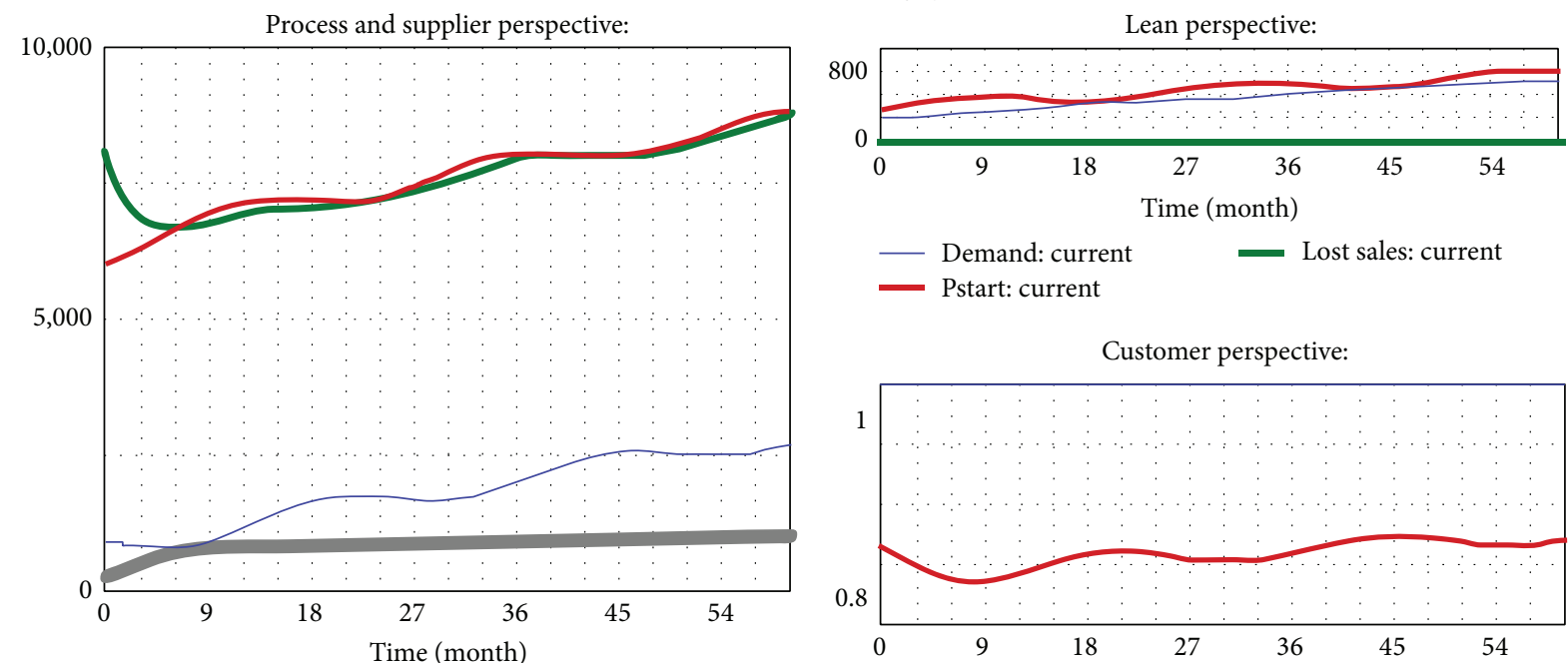

Customer perspective:
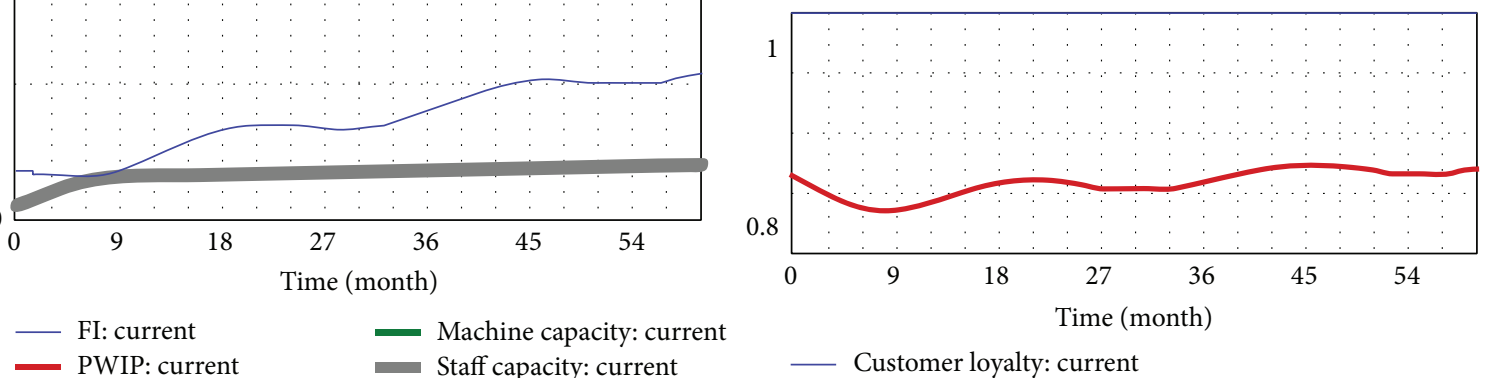

Financial perspective:

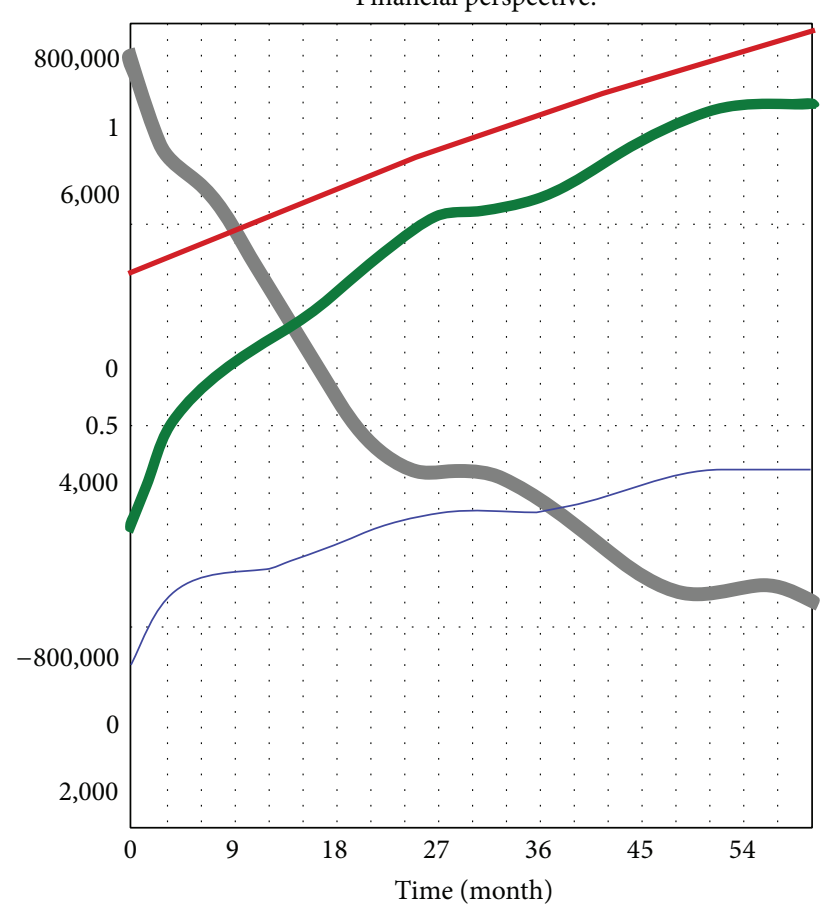

Customer loyalty: current

_ Recommendations: current

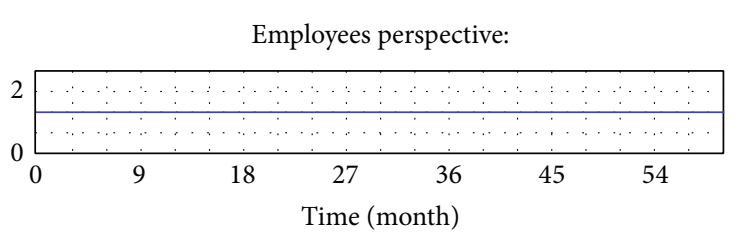

_ Staff utilization: current

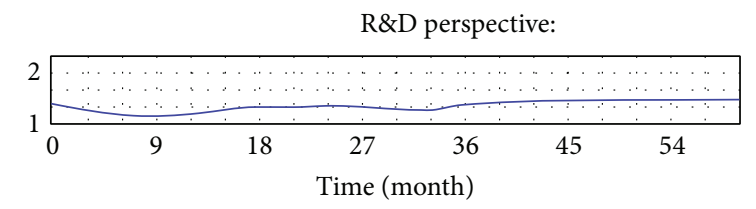

_ "R\&D activity": current

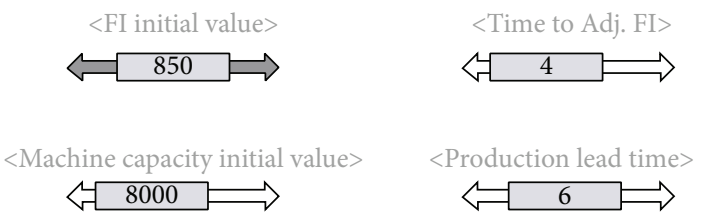

$\begin{array}{ll}- \text { EVA }^{\mathrm{nx}}: \text { current } & \text { RoCE: current } \\ - \text { Profit standard: current } & \text { Unit throughput cost: current }\end{array}$

FIGURE 10: The "Inventory Infusion" scenario.

it may be much easier to interrupt the normal production control and for a limited time let the system run on a much higher production rate virtually resulting in an "Inventory Infusion," instead of changing basic system functioning.

To sum up, we have combined system dynamics and BSC in an experimental setup in order to test different lean strategies and their effects on profit. The results from each learning scenario are then used to modify and try a new scenario that could be used by managers for further strategic learning and reflections. It is important to realize that our purpose has not been to build a complete model of the company's "real" world or complete BSC. Our main idea has been to formulate a simple problem in a system dynamic microworld and to use this model for a number of simulations. 


\section{Discussion and Conclusions}

Reverting to our research framework in Figure 2, our purpose was to build a "study-design" based on the conceptual domain and the methodology domain and then investigate this "study-design" by means of a number of simulations and scenarios ("experimental paths") based on different types of not only assumptions relating to the initial settings but also assumptions relating to structural company parameters.

The lab experiments allow us to adjust the setup of the simulations so as to find parameter values that improve the financial result and thereby we improve the strategic learning process.

Our research idea was motivated by two factors: a growing pressure on companies to adapt to more holistic models [1-3] and our wish to demonstrate that a system dynamic approach is a relevant methodology to improve and increase the insight into BSC through its definitions and techniques for cause-and-effect, time-lags, and feedbacks [12, 22].

Existing accounting literature has focused on static BSCs and nondynamic setups, but this paper has focused on a system dynamic approach using the concept of social and mental elements inspired by Forrester $[57,103]$ with a feedback and double loop learning approach [76].

Our research shows that minor changes in a single endogenous variable may cause the system to change considerably. Referring to our research framework in Figure 2, this paper contributes in two respects. First, it makes a conceptual contribution that focuses on the BSC model building; we improve the learning by doing by showing the outcome of four simple lean simulation scenarios on predefined and lagged financial indicators.

Second, we also provide a useful contribution to the design and the quantification of the BSC by including the changes for both the short and the long runs and the time delays between performance measures and perspectives, something that has been emphasized several times in the literature as the "trade-off" assumptions [61]. Real world causality is not unidirectional but multidirectional because of interdependencies between people and systems. Argyris [28] was one of the first to discuss this phenomenon. The use of flow and stock concepts also allows us to incorporate the most important delays, and when we combine the cause-and-effect consequences and the time delays, we are able to use the system dynamics BSC model for specific simulation scenarios, an area scarcely discussed in the management accounting literature, but definitely at the core of system dynamics $[62,77]$.

Finally, our calibrated model gives us the possibility to experiment in order to obtain strategic learning feedbacks through BSC simulation scenarios by changing a few input performance measures shown in the cockpit display: "FI initial value" (i.e., finished inventory value), "Time to Adj. FI" (i.e., time to adjust to finished inventory level), "Machine Capacity initial value" (i.e., machine capacity level), and "Production Lead Time" (i.e., production lead time). The results from the feedback give managers the possibilities not only to evaluate the operational strategy over time, but also to learn how to operationalize the strategy. The feedback information is one of the most important cornerstones of strategic learning hypotheses discussed in performance management not only in theory $[19,46]$ but also in reality [11]. The simulation results aim at stimulating the perception of decision-makers, obliging them to question their assumptions about how their business world works [92]. The model of a BSC may evolve from the premature stage to its more mature stages, where it might be considered a theory of the specific firm [104].

The failure not to account for relevant leading indicators will lead to a reduction in the information content of these nonfinancial measures. Such failures are potentially costly for (a) managers using these measures for business decisions, (b) persons charged with the governance of firms (e.g., board of directors, logistics, CFOs, and controllers) using these measures for control, and (c) market stakeholders using these measures to guide investment decisions [15].

Because stakeholders are external to the firm, they will derive benefits from knowledge about a few metrics they can use to better forecast outcomes, which, in turn, can yield more efficient resource allocations (Ittner 2008). Our scenario illustrations also give at least some weak indications of when and how different KPIs have implications for the financial perspective, given a specific model setup, which is an issue that has been discussed in the literature concerning nonfinancial measures and their influence on financial performance [18, 40]. The validity of the model will clearly increase if we go through the stages mentioned in the business analytics literature [64] and use creativity and soft tools in combination with system dynamics and statistics. This procedure would, however, require much more data from the company.

By converting an existing BSC into an analytical model, the employees and the company get a common language for discussing strategy, which is an important aspect to ensure strategic success $[59,67,86]$. Yet in spite of the powerful contribution of system dynamics to problem solving, system dynamics is seldom mentioned in the management accounting and control literature. This is particularly remarkable in light of the astonishing success of other related theories such as the importance of feedbacks in general for accountants (e.g., in the Fifth Discipline, [59]). However, the idea of BSC and the "business analytics" (and big-data) both emphasize the use of quantitative modeling for management control, which per se will focus the accountants on more quantitative methods for evaluating control problems. Also new groups within LinkedIn have called for the use of system dynamics for other management control concepts.

Future research within the methodology area should concentrate on defining the problem in more detail and on improving the transparency of a model by extending and testing it with actual or historical data and mental information, which is what is called a data-driven modeling approach. Another interesting theme could be to incorporate uncertainty and the concept of "balance" into the BSC framework or to integrate the planning and budget system under this framework [105]. Because the design of BSC is being undertaken by academics and participants from a wide variety of disciplines (accountants, operations and logistics managers, business strategists, human resource managers, etc.), 
the biggest hurdle that faces such a modeling approach is to get academics to cross these functional boundaries.

\section{Conflict of Interests}

The authors declare that there is no conflict of interests regarding the publication of this paper.

\section{Acknowledgments}

The authors want to thank two anonymous reviewers for their comments and relevant suggestions. The authors are also grateful to the case company for allowing them to use their materials and other documents and for their support and comments on this research. The authors gratefully acknowledge research assistance from P. Ewing, Stockholm School of Economics, and L. Lundahl. This research is supported by data generously provided by the anonymous host company. Proprietary data beyond the data disclosed in this paper is not available.

\section{References}

[1] F. de Geuser, S. Mooraj, and D. Oyon, "Does the balanced scorecard add value? Empirical evidence on its effect on performance," European Accounting Review, vol. 18, no. 1, pp. 93-122, 2009.

[2] E. Wiersma, "For which purposes do managers use balanced scorecards? An empirical study," Management Accounting Research, vol. 20, no. 4, pp. 239-251, 2009.

[3] D. Otley, "Management control and performance management: whence and whither?" The British Accounting Review, vol. 35, no. 4, pp. 309-326, 2003.

[4] A. G. Hopwood, "Management accounting research in a changing world," Journal of Management Accounting Research, vol. 20, no. 1, pp. 3-13, 2008.

[5] R. H. Chenhall and K. Langfield-Smith, "Adoption and benefits of management accounting practices: an Australian study," Management Accounting Research, vol. 9, no. 1, pp. 1-19, 1998.

[6] C. Guilding, K. S. Cravens, and M. Tayles, "An international comparison of strategic management accounting practices," Management Accounting Research, vol. 11, no. 1, pp. 113-135, 2000.

[7] R. S. Kaplan, "The competitive advantage of management accounting," Journal of Management Accounting Research, vol. 18, no. 1, pp. 127-135, 2006.

[8] T. Malmi and D. A. Brown, "Management control systems as a package-opportunities, challenges and research directions," Management Accounting Research, vol. 19, no. 4, pp. 287-300, 2008.

[9] T. H. Davenport, "Competing on analytics," Harvard Business Review, vol. 84, no. 1, pp. 98-108, 2006.

[10] J. Birnberg, M. Shields, and S. Young, "The case for multiple research methods in empirical management accounting research (with an illustration from budget setting)," Journal of Management Accounting Research, vol. 2, pp. 33-66, 1990.

[11] R. H. Chenhall, "Integrative strategic performance measurement systems, strategic alignment of manufacturing, learning and strategic outcomes: an exploratory study," Accounting, Organizations and Society, vol. 30, no. 5, pp. 395-422, 2005.
[12] C. D. Ittner and D. F. Larcker, "Assessing empirical research in managerial accounting: a value-based management perspective," Journal of Accounting \& Economics, vol. 32, no. 1-3, pp. 349-410, 2001.

[13] K. A. Merchant, W. A. van der Stede, and L. Zheng, "Disciplinary constraints on the advancement of knowledge: the case of organizational incentive systems," Accounting, Organizations and Society, vol. 28, no. 2-3, pp. 251-286, 2003.

[14] A. Neely, "The performance measurement revolution: why now and what next?" International Journal of Operations \& Production Management, vol. 19, no. 2, pp. 205-228, 1999.

[15] C. D. Ittner and D. F. Larcker, "Innovations in performance measurement: trends and research implications," Journal of Management Research, vol. 10, pp. 205-238, 1998.

[16] C. D. Ittner, "Does measuring intangibles for management purposes improve performance? A review of the evidence," Accounting and Business Research, vol. 38, no. 3, pp. 261-272, 2008.

[17] R. D. Banker, G. Potter, and D. Srinivasan, "An empirical investigation of an incentive plan that includes nonfinancial performance measures," The Accounting Review, vol. 75, no. 1, pp. 6592, 2000 .

[18] S. S. Dikolli and K. L. Sedatole, "Improvements in the information content of nonfinancial forward-looking performance measures: a taxonomy and empirical application," Journal of Management Accounting Research, vol. 19, no. 1, pp. 71-104, 2007.

[19] R. S. Kaplan and D. P. Norton, "Using the balanced scorecard as a strategic management system," Harvard Business Review, vol. 85, no. 7-8, pp. 150-194, 2007.

[20] R. S. Kaplan and D. P. Norton, The Execution Premium Linking Strategy to Operations for Competitive Advantage, Harvard Business Press, Boston, Mass, USA, 2008.

[21] D. J. Teece, "Strategies for managing knowledge assets: the role of firm structure and industrial context," Long Range Planning, vol. 33, no. 1, pp. 35-54, 2000.

[22] D. P. Norton, "Is management finally ready for the 'systems approach'?” Balanced Scorecard Report, vol. 2, no. 5, 2000.

[23] M. Hudson, A. Smart, and M. Bourne, "Theory and practice in SME performance measurement systems," International Journal of Operations and Production Management, vol. 21, no. 8, pp. 1096-1115, 2001.

[24] H. Sundin, M. Granlund, and D. A. Brown, "Balancing multiple competing objectives with a balanced scorecard," European Accounting Review, vol. 19, no. 2, pp. 203-246, 2010.

[25] D. Brinberg and J. E. McGrath, Validity and the Research Process, SAGE Publications, New York, NY, USA, 1985.

[26] H. A. Simon, "Bounded rationality and organizational learning," Organization Science, vol. 2, no. 1, pp. 125-134, 1991.

[27] J. Bisbe, J.-M. Batista-Foguet, and R. Chenhall, "Defining management accounting constructs: a methodological note on the risks of conceptual misspecification," Accounting, Organizations and Society, vol. 32, no. 7-8, pp. 789-820, 2007.

[28] C. Argyris, "Single-loop and double-loop models in research on decision making," Administrative Science Quarterly, vol. 21, no. 3, pp. 363-375, 1976.

[29] C. Argyris, Teaching Smart People How to Learn, Harvard Business Review, 1991.

[30] R. S. Kaplan and D. P. Norton, "The balanced scorecardmeasures that drive performance," Harvard Business Review, vol. 70, no. 1, pp. 71-79, 1992. 
[31] R. S. Kaplan and D. P. Norton, The Balanced ScorecardTranslating Strategy into Action, Harvard Business School Press, Boston, Mass, USA, 1996.

[32] I. Cobbold, G. Lawrie, and K. Issa, "Designing a strategic management system using the third-generation balanced scorecard: a case study," International Journal of Productivity and Performance Management, vol. 53, no. 7, pp. 624-633, 2004.

[33] Excitant, 2011, http://www.excitant.co.uk/pages/bsc_four_generations.htm.

[34] G. Speckbacher, J. Bischof, and T. Pfeiffer, "A descriptive analysis on the implementation of Balanced Scorecards in Germanspeaking countries," Management Accounting Research, vol. 14, no. 4, pp. 361-387, 2003.

[35] E. W. Anderson, C. Fornell, and D. R. Lehmann, "Customer satisfaction, market share, and profitability: findings from Sweden," Journal of Marketing, vol. 58, no. 3, pp. 53-66, 1994.

[36] E. W. Anderson, C. Fornell, and R. T. Rust, "Customer satisfaction, productivity, and profitability: differences between goods and services," Marketing Science, vol. 16, no. 2, pp. 129-145, 1997.

[37] C. Ashton, Strategic Performance Measurement: Transforming Corporate Performance by Measuring and Managing the Drivers of Business Success, Business Intelligence, London, UK, 1997.

[38] A. J. Rucci, S. P. Kirn, and R. T. Quinn, The Employee-Customer Profit Chain at Sears, Harvard Business Review, 1998.

[39] C. D. Ittner and D. F. Larcker, "Coming up Short on Nonfinancial Performance Measurement," Harvard Business Review, vol. 81, no. 11, pp. 88-95, 2003.

[40] E. Wiersma, "An exploratory study of relative and incremental information content of two non-financial performance measures: field study evidence on absence frequency and on-time delivery," Accounting, Organizations and Society, vol. 33, no. 23, pp. 249-265, 2008.

[41] T. Malmi, "Balanced scorecards in Finnish companies: aresearch note," Management Accounting Research, vol. 12, no. 2, pp. 207-220, 2001.

[42] J. C. F. de Winter, D. Dodou, and P. A. Wieringa, "Exploratory factor analysis with small sample sizes," Multivariate Behavioral Research, vol. 44, no. 2, pp. 147-181, 2009.

[43] A. S. Ghasemi, "Using structural equation modeling in causal relationship design for balanced-scorecards strategic map," in Proceedings of the World Academy of Science, Engineering \& Technology Conference, 2009.

[44] A. Neely, H. Richards, J. Mills, K. Platts, and M. Bourne, "Designing performance measures: a structured approach," International Journal of Operations \& Production Management, vol. 17, no. 11, pp. 1131-1152, 1997.

[45] E. G. Flamholtz, "The process of measurement in managerial accounting: a psycho-technical systems perspective," Accounting, Organizations and Society, vol. 5, no. 1, pp. 31-42, 1980.

[46] A. Ferreira and D. Otley, "The design and use of performance management systems: an extended framework for analysis," Management Accounting Research, vol. 20, no. 4, pp. 263-282, 2009.

[47] Z. Hoque and W. James, "Linking balanced scorecard measures to size and market factors: impact on organizational performance," Journal of Management Accounting Research, vol. 12, no. 1, pp. 1-17, 2000.

[48] H. Nørreklit, "The balance on the balanced scorecard-a critical analysis of some of its assumptions," Management Accounting Research, vol. 11, no. 1, pp. 65-88, 2000.
[49] M. A. Malina and F. H. Selto, "Choice and change of measures in performance measurement models," Management Accounting Research, vol. 15, no. 4, pp. 441-469, 2004.

[50] M. A. Malina and F. M. Selto, Causality in a Performance Measurement Model, WP, MIT, Boston, Mass, USA, 2004.

[51] H. Nørreklit and F. Mitchell, "Contemporary issues on the balance scorecard," Journal of Accounting \& Organizational Change, vol. 10, no. 4, p. 431, 2014.

[52] S. Brignall, "The unbalanced scorecard: a social and environmental critique," in Proceedings of the 3rd International Conference on Performance Measurement and Management, Boston, Mass, USA, July 2002.

[53] M. A. Malina, H. S. O. Nørreklit, and F. H. Selto, "Relations among measures, climate of control, and performance measurement models," Contemporary Accounting Research, vol. 24, no. 3, pp. 662-982, 2007.

[54] C. W. J. Granger, "Investigating causal relations by econometric models and cross-spectral methods," Econometrica, vol. 37, no. 3, pp. 424-238, 1969.

[55] P. Senge and J. W. Forrester, "Test for building confidence in system dynamics models," in TIMS Studies in the Management Science, vol. 14, pp. 209-228, North Holland Publishing, 1980.

[56] P. N. Bukh and T. Malmi, "Re-examining the cause-andeffect principle of the balanced scorecard," in Accounting in Scandivavia-The Northern Lights, S. Jönsson and J. Mouritsen, Eds., Liber \& Copenhagen Business School Press, 2005.

[57] J. W. Forrester, "Industrial dynamics: a major breakthrough for decision makers," Harvard Business Review, pp. 37-66, 1958.

[58] K. Warren, "Why has feedback systems thinking struggled to influence strategy and policy formulation? Suggestive evidence, explanations and solutions," Systems Research and Behavioral Science, vol. 21, no. 4, pp. 331-347, 2004.

[59] P. Senge, The Fifth Discipline: The Art \& practice of the Learning Organization, Random House Business, 1990.

[60] R. S. Kaplan and D. P. Norton, "Linking the balanced scorecard to strategy," California Management Review, vol. 39, pp. 53-79, 1996.

[61] R. D. Banker, H. Chang, S. N. Janakiraman, and C. Konstans, "A balanced scorecard analysis of performance metrics," European Journal of Operational Research, vol. 154, no. 2, pp. 423-436, 2004.

[62] J. D. Sterman, Business Dynamics System Thinking and Modelling for a Complex World, McGraw-Hill Higher Education, Boston, Mass, USA, 2000.

[63] G. K. Kanji, "Performance measurement system," Total Quality Management, vol. 13, no. 5, pp. 715-728, 2002.

[64] T. H. Davenport and J. Kim, Keeping Up with the Quants, Harvard Business Review Press, 2013.

[65] Z. Hoque, "20 years of studies on the balanced scorecard: trends, accomplishments, gaps and opportunities for future research," The British Accounting Review, vol. 46, no. 1, pp. 33-59, 2014.

[66] D. C. Lane, "Modelling as learning: a consultancy methodology for enhancing learning in management teams," European Journal of Operational Research, vol. 59, no. 1, pp. 64-84, 1992.

[67] J. A. M. Vennix, "Group model-building: tackling messy problems," System Dynamics Review, vol. 15, no. 4, pp. 379-401, 1999.

[68] A. D. Smith, "The strategic role of knowledge and innovation systems thinking," International Journal of Business \& Systems Research, vol. 1, no. 2, pp. 200-215, 2007.

[69] J. D. W. Morecroft and J. D. Sterman, "Modelling for learning," European Journal of Operational Research, vol. 59, no. 1, 1992. 
[70] G. P. Richardson and D. F. Andersen, "Teamwork in group model building," System Dynamics Review, vol. 11, no. 2, pp. 113137, 1995.

[71] K. Warren and P. Langley, "The effective communication of system dynamics to improve insight and learning in management education," Journal of the Operational Research Society, vol. 50, no. 4, pp. 396-404, 1999.

[72] R. D. H. Warburton, "An analytical investigation of the bullwhip effect," Production and Operations Management, vol. 13, no. 2, pp. 150-160, 2004.

[73] R. D. H. Warburton, J. P. E. Hodgson, and E. H. Nielsen, "Exact solutions to the supply chain equations for arbitrary, time-dependent demands," International Journal of Production Economics, vol. 151, pp. 195-205, 2014.

[74] D. H. Meadows, "The unavoidable A priori," in Elements of the System Dynamics Method, J. Randers, Ed., MIT Press, Cambridge, Mass, USA, 1980.

[75] P. B. Checkland, Systems Thinking, Systems Practice, John Wiley \& Sons, 1998.

[76] C. Argyris and D. A. Schön, Organizational Learning: A Theory of Action Perspective, Addison-Wesley, New York, NY, USA, 1978.

[77] G. Coyle, "Qualitative and quantitative modelling in system dynamics: some research questions," System Dynamics Review, vol. 16, no. 3, pp. 225-244, 2000.

[78] D. Katz and R. L. Kahn, The Social Psychology of Organizations, University of North Carolina Press, Chapel Hill, NC, USA, 1978.

[79] J. G. March and H. A. Simon, Organizations, Wiley-Blackwell, Hoboken, NJ, USA, 1958.

[80] E. F. Wolstenholme, "Qualitative vs quantitative modelling: the evolving balance," Journal of the Operational Research Society, vol. 50, no. 4, pp. 422-428, 1999.

[81] M. A. Malina and F. H. Selto, "Communicating and controlling strategy: an empirical study of the effectiveness of the balanced scorecard," Journal of Management Accounting Research, vol. 13, no. 1, pp. 47-90, 2001.

[82] J. W. Forrester, System Dynamics and the Lessons of 35 Years, WP MIT, 1991.

[83] R. L. Eberlein and D. W. Peterson, "Understanding models with Vensim," European Journal of Operational Research, vol. 59, no. 1, pp. 216-219, 1992.

[84] H. A. Akkermans and K. E. van Oorschot, "Relevance assumed: a case study of balanced scorecard development using system dynamics," Journal of the Operational Research Society, vol. 56, no. 8, pp. 931-941, 2005.

[85] S. Nielsen and E. H. Nielsen, "System dynamics modelling for a balanced scorecard: computing the influence of skills, customers, and work in process on the return on capital employed," Management Research News, vol. 31, no. 3, pp. 169188,2008

[86] K. Warren, "Improving strategic management with the fundamental principles of system dynamics," System Dynamics Review, vol. 21, no. 4, pp. 329-350, 2005.

[87] F. Barnabè and C. Busco, "The causal relationships between performance drivers and outcomes: reinforcing balanced scorecards' implementation through system dynamics models," Journal of Accounting \& Organizational Change, vol. 8, no. 4, pp. 528-538, 2012.

[88] F. Barnabè, "A 'system dynamics-based Balanced Scorecard' to support strategic decision making: insights from a case study," International Journal of Productivity and Performance Management, vol. 60, no. 5, pp. 446-473, 2011.
[89] J. Womack and D. T. Jones, "From lean production to the lean enterprise," Harvard Business Review, vol. 72, no. 2, pp. 93-103, 1994.

[90] J. P. Womarck and D. T. Jones, Lean Thinking, Simon \& Schuster, London, UK, 2003.

[91] R. L. Ackoff, "Why few organizations adopt systems thinking," Systems Research and Behavioral Science, vol. 23, no. 5, pp. 705708, 2006.

[92] A. P. de Geus, "Modelling to predict or to learn?" European Journal of Operational Research, vol. 59, no. 1, pp. 1-5, 1992.

[93] R. L. Ackoff, "On the use of models in corporate planning," Strategic Management Journal, vol. 2, no. 4, pp. 353-359, 1981.

[94] H. A. Simon, "Prediction and prescription in systems modeling," Operations Research, vol. 38, no. 1, pp. 7-14, 1990.

[95] K. Warren, Strategic Management Dynamics, John Wiley \& Sons, Chichester, UK, 2008.

[96] R. S. Kaplan and D. P. Norton, Strategy Maps, Harvard Business School Press, Boston, Mass, USA, 2004.

[97] B. H. Maskell and F. A. Kennedy, "Why do we need lean accounting and how does it work?" Journal of Corporate Accounting \& Finance, vol. 18, no. 3, pp. 59-73, 2007.

[98] R. R. Niven, Balanced Scorecard Step by Step: Maximizing Performance and Maintaining Results, Wiley, Ontario, Canada, 2nd edition, 2006.

[99] D. J. Collis and M. G. Rukstad, "Can you say what your strategy is?” Harvard Business Review, vol. 86, no. 4, pp. 82-137, 2008.

[100] J. W. Forrester, Industrial Dynamics, MIT Press, Cambridge, Mass, USA, 1961.

[101] M. C. Deluzio, "Management accounting in a just-in-time environment," Journal of Cost Accouting, pp. 6-14, 1993.

[102] S. Samaddar and T. Kaul, "Effect of setup and processing time reductions on WIP in the JIT production systems," Management Science, vol. 41, no. 7, pp. 1263-1265, 1995.

[103] J. W. Forrester, System Dynamics and K-12 Teachers, A Lecture at the University of Virginia School of Education, Massachusetts Institute of Technology, Cambridge, Mass, USA, 1996.

[104] M. Schwaninger and S. Grösser, "System dynamics as modelbased theory building," Systems Research and Behavioral Science, vol. 25, no. 4, pp. 447-465, 2008.

[105] M. Beasley, A. Chen, K. Nunez, and L. Wright, "Working hand in hand: balanced scorecard and enterprise risk management," Strategic Finance, vol. 88, no. 9, pp. 49-55, 2006. 


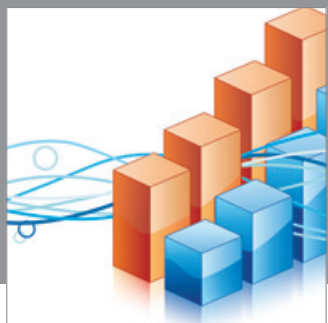

Advances in

Operations Research

mansans

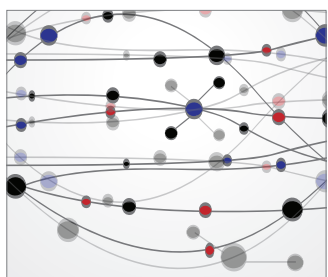

The Scientific World Journal
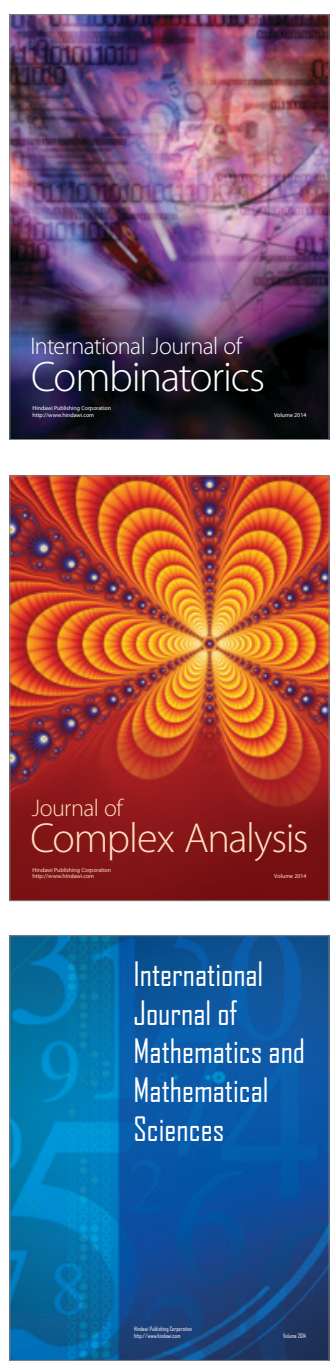
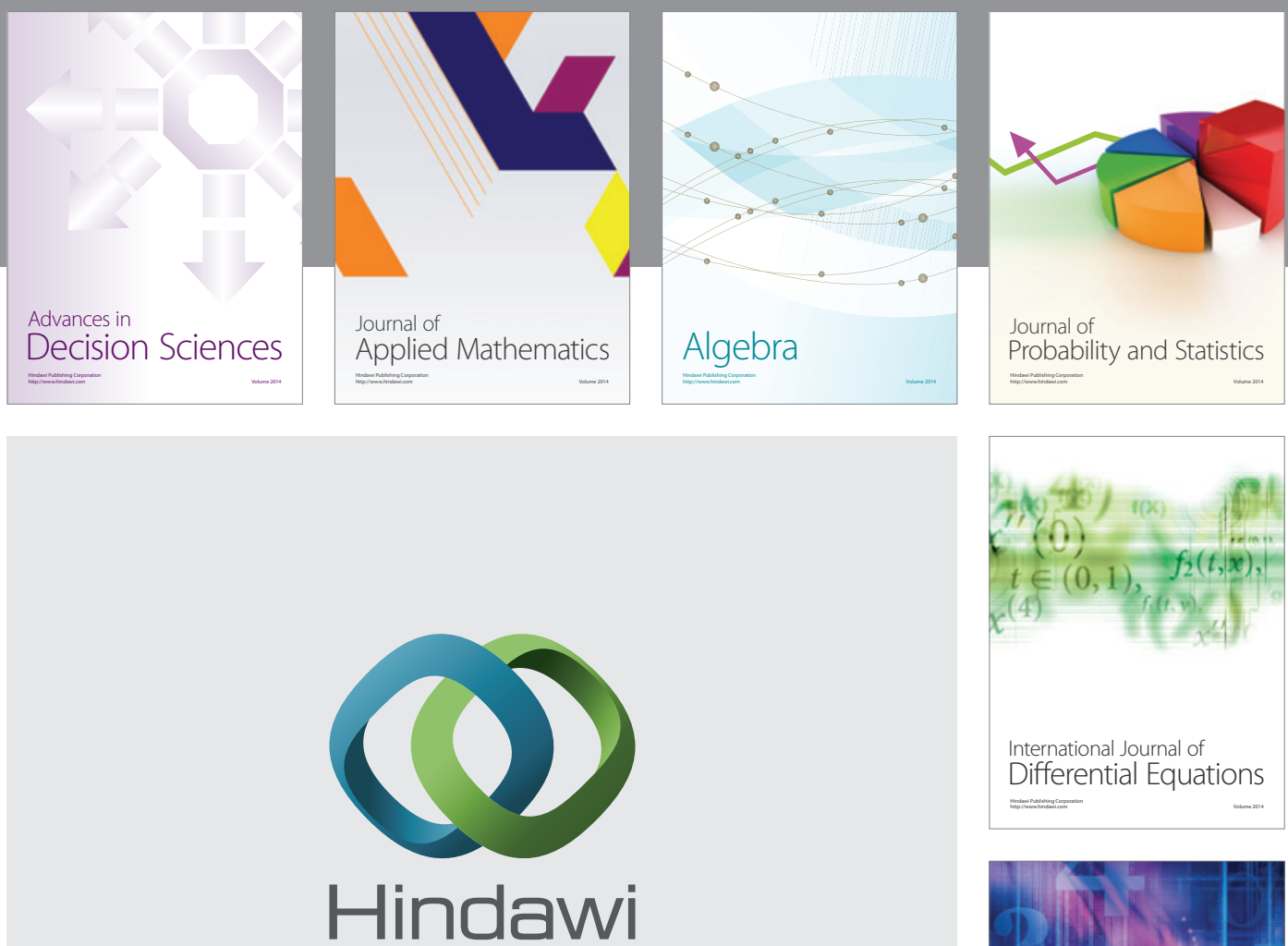

Submit your manuscripts at http://www.hindawi.com
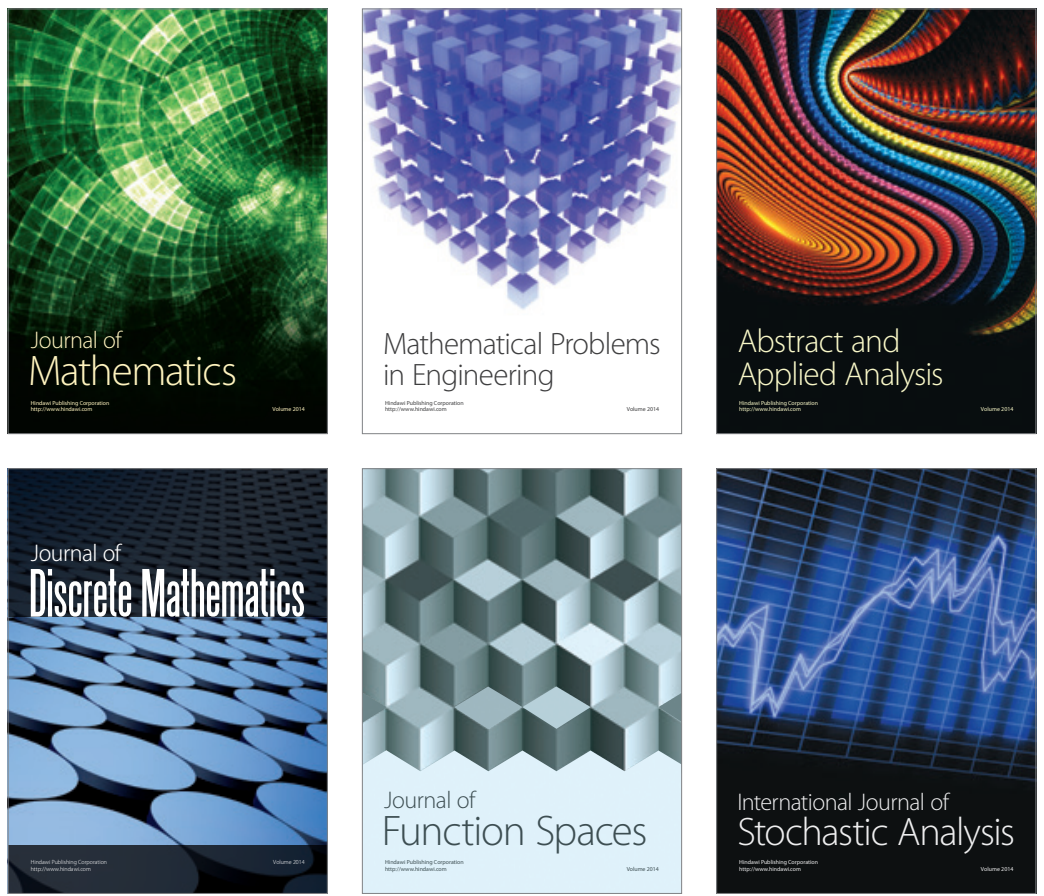

Journal of

Function Spaces

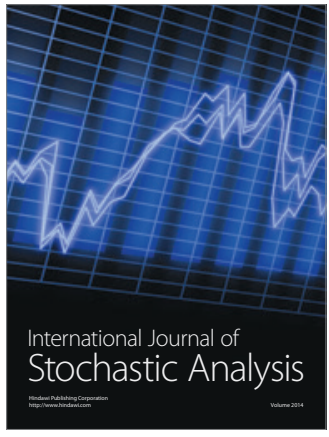

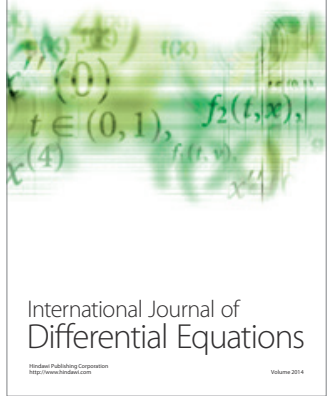
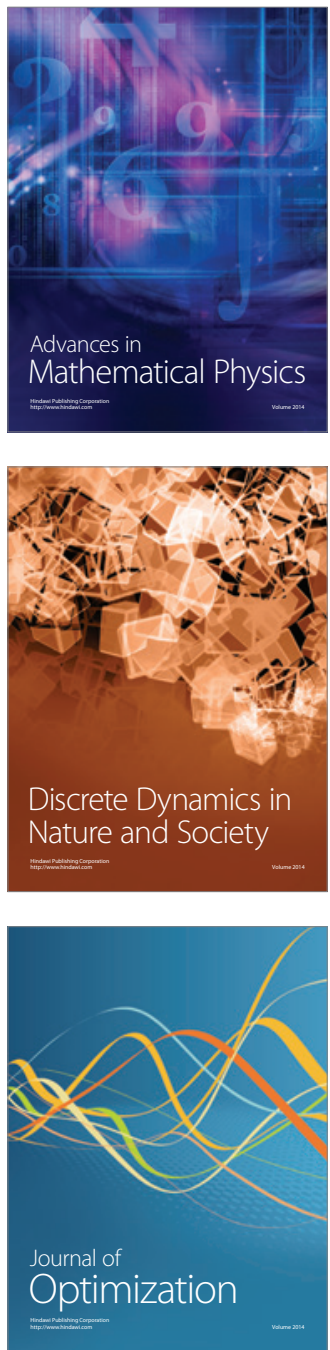